\title{
cuerpos Significantes. Nuevas travesías
}

vialécticas

SILVIa cITro

universinan de Buenos Aires -

conicet, Argentina

(Resumen: Este artículo traza una breve genealogía de mis investigaciones socioantropológicas sobre la corporalidad en Argentina, partiendo del entrecruzamiento entre ciertas experiencias intersubjetivas que involucraron intensamente la corporalidad desde lo sensorial y emotivo, las performances artísticas y las etnografías realizadas desde mediados de los años noventa. A partir de esta travesía inicial, que vincula experiencias personales y producción artística e intelectual, en un contexto geopolítico e histórico determinado, discuto tres problemáticas teóricometodológicas claves en el campo actual de los estudios sobre el cuerpo en América Latina, por cuanto constatamos que también otros colegas de nuestros países las comparten. En primer lugar, sobre los modos en que nuestras

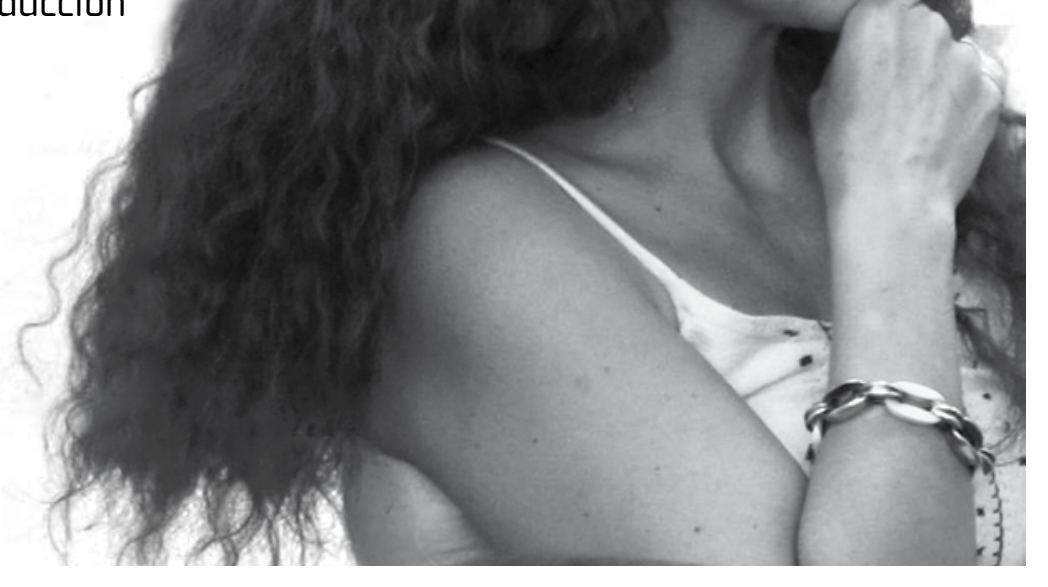


corporalidades y, agregaría, nuestras producciones intelectuales sobre el cuerpo son el resultado de un complejo entramado de materialidades biológicas, tecnologías, procesos psicológicos, intersubjetivos, históricos y político-culturales que entrelazan sensaciones, movimientos, afectividades, imágenes, representaciones y discursos. Por ello, creemos que el desafío ante tal complejidad es evitar caer en un reduccionismo del cuerpo que lo someta a la mirada unilateral de una sola disciplina, y tratar de avanzar, en cambio, hacia una progresiva interdisciplinariedad. En segundo lugar, entender cómo esa corporalidad compleja es fruto de una historia y un contexto afectivo-familiar y social que se inscriben poderosamente en nuestra carne y la delimitan a partir de múltiples, reiteradas y sutiles relaciones, a la vez que esa misma carne es sede de nuestra agencia, creatividad, singularidad subjetiva e incluso de nuestra resistencia político cultural. Esto nos enfrenta al desafío de analizar estas complejas dimensiones de un cuerpo que es objeto de poder y a la vez encarnación de nuestra agencia. Una vez más, intentando evitar reduccionismos, reseñaremos cómo nuestras investigaciones han buscado articular diferentes abordajes teórico-metodológicos en una perspectiva dialéctica que confronta ciertos abordajes fenomenológicos con los semióticos y posestructuralistas. El tercer desafío que aquí desarrollaremos está vinculado a nuestra doble trayectoria en el campo académico-intelectual y en las artes de la performance, intentando demostrar que los cuerpos en movimiento, los cuerpos expresivos de los juegos creativos, los rituales compartidos y las artes son también "buenos para pensar". Reseñaremos entonces cómo, en estos últimos años, con nuestro equipo hemos comenzado a ensayar prácticas cognoscitivas que involucran más decididamente las experiencias corporales, estético-sensibles y emocionales intersubjetivas, incluidas aquellas provenientes de los modos de saber-hacer propios de nuestras tradiciones socioculturales indígenas y afroamericanas. De este modo, intentamos una "antropología de y desde los cuerpos" en los modos de practicar la etnografía, difundir nuestras investigaciones y desarrollar los procesos de enseñanza-aprendizaje con nuestros estudiantes. Finalmente, desde una perspectiva latinoamericana decolonial, destacamos la importancia epistemológica y también política de construir nuevos modos de generar conocimientos en nuestras academias, revalorizando el rol de las experiencias corporales, los vínculos colectivos y los intercambios interculturales, a la manera de compañeros dialécticos de las formas de lectoescritura y oralidad individual que heredamos de la colonialidad-modernidad occidental.

\section{(Palabras ClaVE: [uerpos, danzas, antropología, dialéctica, decolonialidad.}


(Abstract: This article draws a brief genealogy on my socio-anthropological researches on embodiment in Argentina, starting from the crosslinking among some inter-subjective experiences which involve, in an intense way, the corporality, from the sensorial and the emotional, the artistic performances and the ethnographies realized since mid-gos. From this initial travel, linking personal experiences with artistic and intellectual production in a specific geopolitical and historical environment, I discuss three key theoreticalmethodological problems in the current field of the studies about the body in Latin America, as soon as we find they are shared with other colleagues of our countries. In the first place, the way our corporality and I will add, our intellectual production about the body, is the result of a complex network among biologic materiality, technologies, psychological, inter-subjective, historical and politic-cultural processes, which intertwine sensations, movements, affectivities, images, representations and speeches. Therefore, we belief, the challenge before such a complexity involves to avoid fall down in the reductionism of the body, submitting it to a onesided sight of one discipline, and in the contrary, to attempt go ahead into a progressive interdisciplinary work. Second, how

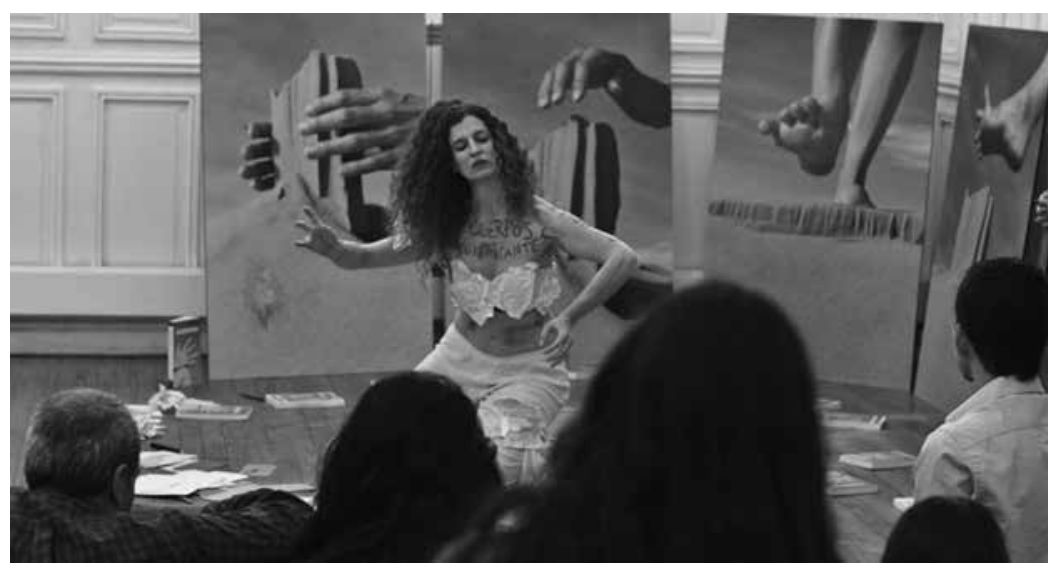
that complex corporality is the result of a history and an environment familiar a social, powerfully inscribed in our Flesh, and delimited it from multiples, reiterated and subtle relations. But at the same time, that same flesh is the site to our agency, creativity, subjective singularity, and even our politic-cultural resistance. 
This confronts us with the challenge about how to analyze these complex dimensions of a body which is object of power and at the same time embodiment of our agency. And one more time trying to avoid reductionisms, we will outline how our researches have look for the articulation of different theoretical-methodological approaches in a dialectic perspective which confronts some Phenomenology with the Semiotics and Post-structuralisms. The third challenge we will develop here, is related to our double trajectory in the scholar-intellectual field and in the performance arts, trying to demonstrate that the moving bodies, the expressive bodies of creative plays, share rituals and arts, are also "good to think". We will outline then how in these last years, we have begun to rehearse cognitive practices with our team, which decidedly involve the estheticsensible and emotional-inter-subjective corporal experiences, included those coming from the ways to know-to do belonging to our Indigenous and Afro-American socio-cultural traditions. In this way, we try an "anthropology of and from the bodies" in the ways of practicing the ethnography, spreading our researches, and developing the teaching-learning process with our students. Finally, from a Latin American De-colonial perspective, we outstand the epistemology and also politic importance of building new ways of create knowledge in our academics, revaluing the role of body experiences, the collective relationships and the inter-cultural exchanges, as dialectic partners of the individual reading-writing ways we inherit of the Western ColonialModernity.

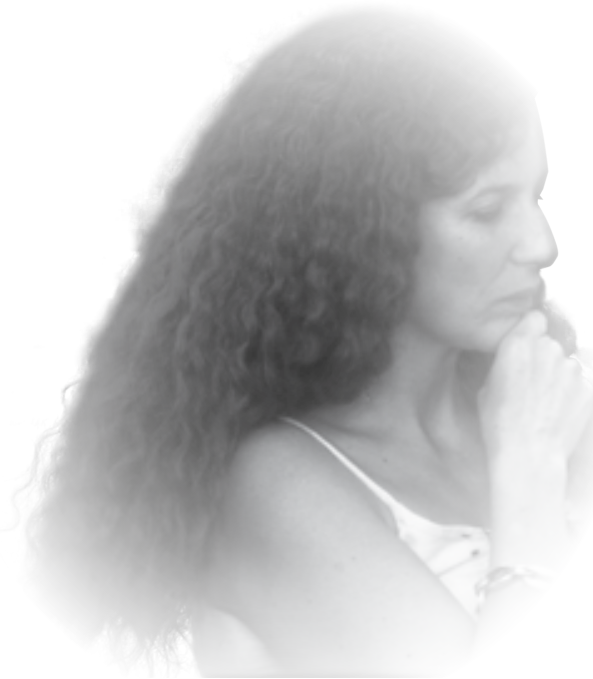

\section{Key Words: Bodies, Dances, Anthropology, Dialectic,}




\section{El presente}

artículo, basado en una conferencia performativa presentada en el Primer Encuentro Nacional de Investigaciones sobre el Cuerpo "El Giro Corporal", se inicia con una reflexión que intenta vincular tres dimensiones existenciales, acontecidas en un contexto geopolítico e histórico específico: la labor de investigación socioantropológica sobre el cuerpo que vengo realizando desde 1997 en la Universidad de Buenos Aires, Argentina; una serie de performances de danza-teatro en las que participé desde aquella época y hasta 2003; y algunas de las experiencias intersubjetivas que involucraron intensamente mi corporalidad, desde lo sensorial y emotivo; tal es el caso de ciertos padecimientos y enfermedades vividos durante ese período. A pesar de los casi 17 años que me he venido dedicando a las investigaciones sobre corporalidades, hasta ahora nunca me había permitido reflexionar, en un marco académico como el que nos convoca, sobre estos cruces entre experiencias personales y producciones artísticas e intelectuales, desde una perspectiva geopolíticamente situada. Si bien en las ciencias sociales, y particularmente en la antropología social, existe ya una importante tradición reflexiva sobre cómo intervienen ciertas dimensiones personales o autobiográficas del investigador en sus perspectivas de análisis y producciones académicas, fueron pocas las veces en que esta reflexividad me llevó a revisar las propias experiencias corporales, como si ellas aún permanecieran alejadas de las ideas más abstracłas, tan características del lenguaje de las teorías y los métodos científicos A pesar del predominio de esta tendencia -propia del racionalismo de la modernidad- a invisibilizar los cuerpos que generan las ideas, cabe recordar que ya a finales del siglo XIX Friedrich Nietzsche señalaba: "no nos corresponde a los filósofos separar el alma del cuerpo [...]. No somos aparatos de objetivación y de registro sin entrañas; sino que hemos de parir continuamente nuestros pensamientos desde el fondo de nuestros dolores y proporcionarles maternalmente todo lo que hay en nuestra sangre, corazón, deseo, pasión, tormento, conciencia, destino, fatalidad" (1995: 39). También Antonin Artaud, algunos años después, destacaba: "nunca hubiera nacido una idea sin el trabajo efectuado un día por el cuerpo". Retomando estas voces disidentes del pasado, diría hoy que con esta propuesta de "auto-etnografías genealógicas" buscamos explorar cómo fueron "paridos" ciertos pensamientos teórico-metodológicos, cuáles fueron "los trabajos efectuados un día por el cuerpo" que dieron nacimiento a esas ideas. De este modo, mi intención es también estimular y provocar, en los posibles investigadores y/o artistas que se acerquen a estas páginas, recorridos reflexivos similares e invitarlos a preguntarse por las raíces experienciales, carnales de sus pensamientos epistemológicos y/o elecciones estéticas y, por qué no, también a animarse a cuestionarlos.

¿Pero qué inspira esta vocación genealógica? Vale aclararlo: no se trała de un mero regodeo posmoderno en el yo del investigador o el artista, autocelebratorio de una pura individualidad, sino, por el contrario, de ejercer sobre nosotros mismos cierta "voluntad de sospecha" que nos muestre el carácter socialmente construido, geopolíticamente situado, de eso que llamamos yo, y de aquello que llamamos teorías u obras. Y aquí, como algunos habrán podido advertir, estoy retomando una tradición hermenéutica que, siguiendo una bella 
expresión de Ricouer (1999), responde a los "maestros de la sospecha" Nietzsche, Marx y Freud. En efecto, pensamos que, en la medida en que ampliemos nuestra conciencia de que somos fruto de esas complejas tramas de contingencias que emergen del haber-habitado en un mundo, podremos abrirnos a la posibilidad de, al menos, intentar crear otros nuevos...!

\section{A partir}

de esta travesía inicial, y moviéndonos ya hacia la segunda parte, reflexionaremos sobre al menos tres problemáticas

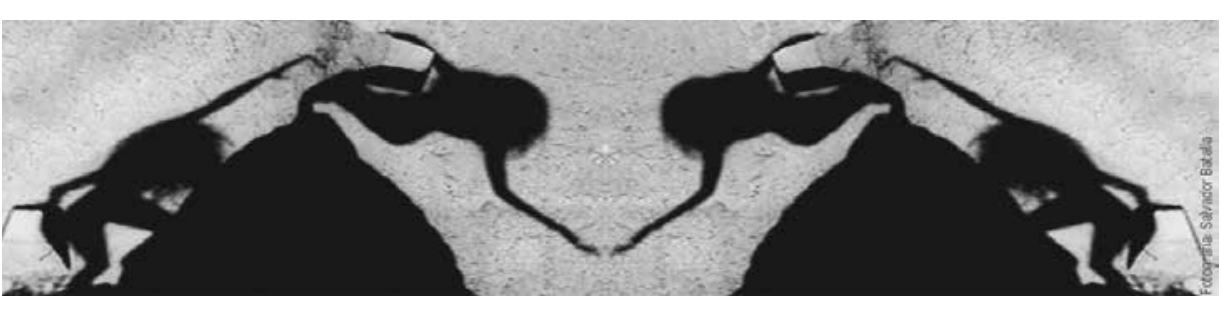
na, por cuanto no solo atraviesan nuestra propia genealogía, sino que también son compartidas con otros colegas: la tendencia a una mayor interdisciplinariedad en nuestras investigaciones; los vínculos y a la vez las brechas entre los abordajes de orientación fenomenológica y los inspirados en el estructuralismo y posestructuralismo; y las relaciones epistemológicas (y políticas) entre nuestras teorías y prácticas corporales. Nos centraremos aquí en la reflexión sobre estas dos últimas cuestiones, planteando como posible respuesta a estas problemáticas un doble movimiento dialéctico. En primer lugar, un abordaje teórico-metodológico que confronta las perspectivas fenomenológicas con las estructuralistas y posestructuralistas, en pos de arribar a una síntesis comprensiva más compleła sobre el rol de la corporalidad en la vida sociocultural. En segundo lugar, ensayando nuevas prácticas cognoscitivas que emergen de la confrontación y posterior síntesis creativa entre las formas de lectoescritura y oralidad individual que heredamos de la colonialidad-modernidad occidental (y que aún son hegemónicas en nuestras academias) y aquellas performances

1 Como sostiene Ricoeur (1999:28), los maestros de la sospecha buscan la “desmitificación”, "la reducción de ilusiones”. Se trata de la voluntad de "descifrar", pues se sospecha que lo que es dado como verdad puede no serlo, y agrega: "En el fondo, la Genealogía de la moral, en el sentido de Nietzsche, la teoría de las ideologías en el sentido marxista, la teoría de los ideales y las ilusiones en el sentido de Freud, representan tres procesos convergentes de la desmitificación [...] los tres comienzan por la sospecha con respecto a las ilusiones de la conciencia y continúan por el ardid del desciframiento; los tres, finalmente, lejos de ser detractores de la "conciencia" apuntan a una extensión de la misma” (1999: 34). Como ejemplo de este ejercicio genealógico de ampliación de la conciencia que conduce a la creación y transformación, podemos citar una de las metáforas nietzscheanas sobre las tres transformaciones que debe atravesar el superhombre: primero debe convertirse en "camello", para tomar sobre sí la pesada carga de la moral invertida; luego transformarse en "león", para criticar la moral del deber-ser, del "tú debes" y luchar por el "yo quiero", por "crearse una libertad"; finalmente, se transforma en "niño", en el creador espontáneo de su propio juego, de los nuevos valores, pues "para el juego de la creación, hace falta una santa afirmación: el espíritu quiere ahora su voluntad, el que ha perdido el mundo quiere ganarse su mundo” (Nietzsche, 1984: 20). 
colectivas que involucran más plenamente la diversidad de experiencias corporales, estético-sensibles y emocionales, incluidas las vinculadas a los saberes y tradiciones culturales indígenas y afroamericanas. Nuestra intención, así, es avanzar hacia nuevas síntesis interculturales en las que los cuerpos en movimiento, los cuerpos expresivos del juego creativo, las artes y los rituales compartidos, sean reconocidos en nuestras académicas como cuerpos significantes, que también son buenos para pensar. Comenzaremos nuestra primera travesía presentando cuatro breves escenas de esta genealogía híbrida, la cual, además de palabras, apelará a imágenes y sonoridades.

\section{Escenas de una genealogía híbrida: entre la antropología, LA DANZA-TEATRO Y LAS EXPERIENCIAS DE PADECIMIENTO-ENFERMEDAD}

\section{UNA ENTUSIASTA SÍNTESIS JUVENIL \\ DE TEORÍAS Y PRÁCTICAS}

En 1997, presenté mi tesis de licenciatura en Antropología Sociocultural en la Universidad de Buenos Aires, titulada "Cuerpos festivo-rituales. Un abordaje desde el rock", que fue una de las primeras abocadas a la corporalidad dentro del campo antropológico de mi país, y justamente ese mismo año realizamos las presentaciones más importantes con mi grupo de danza-teatro Compañía de Andanzas. Yo había sido socializada como antropóloga social en los años noventa en una universidad pública, libre y gratuita, de orientación fundamentalmente marxista, que en esos años encarnó la resistencia al neoliberalismo gobernante. Asimismo, gran parte de mi formación como performer de danza-teatro también aconteció en centros culturales estatales.

En mi tesis abordé las prácticas y representaciones del cuerpo en bandas de rock argentino y, en especial, en una manifestación corporal del público denominada pogo, que se entremezclaba con ciertos rasgos estilísticos de las hinchadas de futbol locales. De estas experiencias, me impactaba la intensidad que adquirían la gestualidad y los movimientos y cómo estas experiencias sensoriales y emotivas intervenían

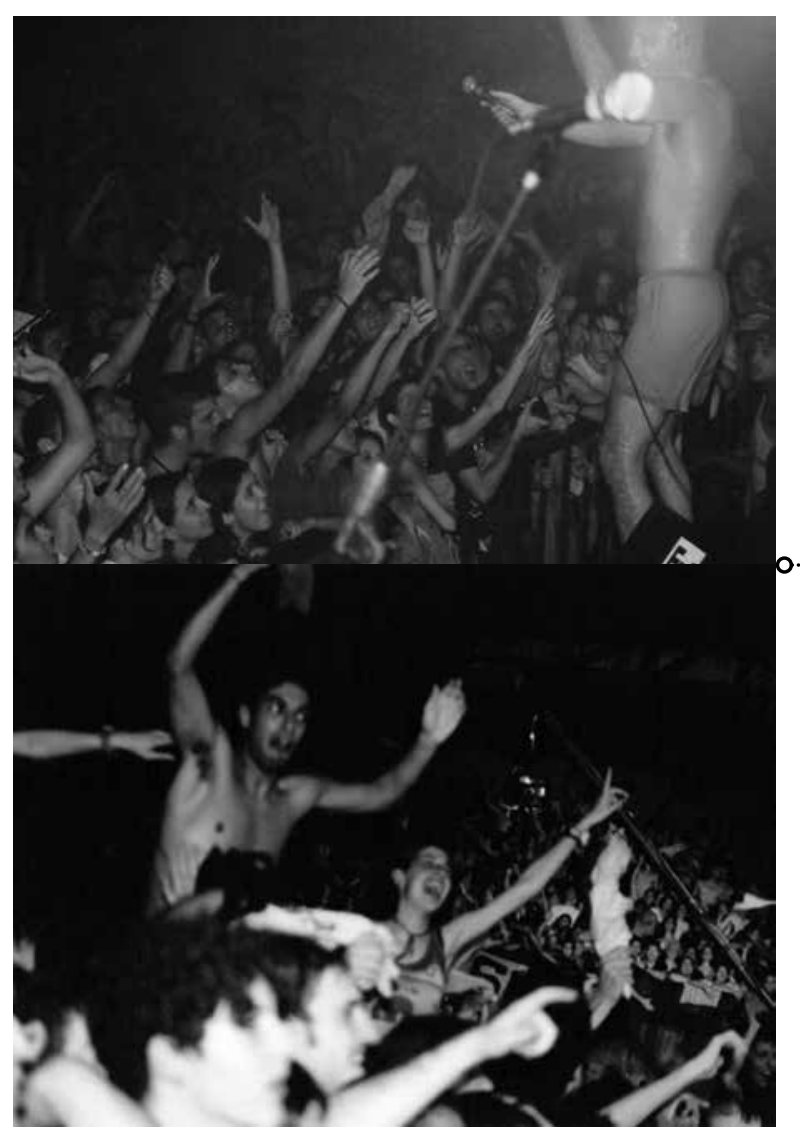




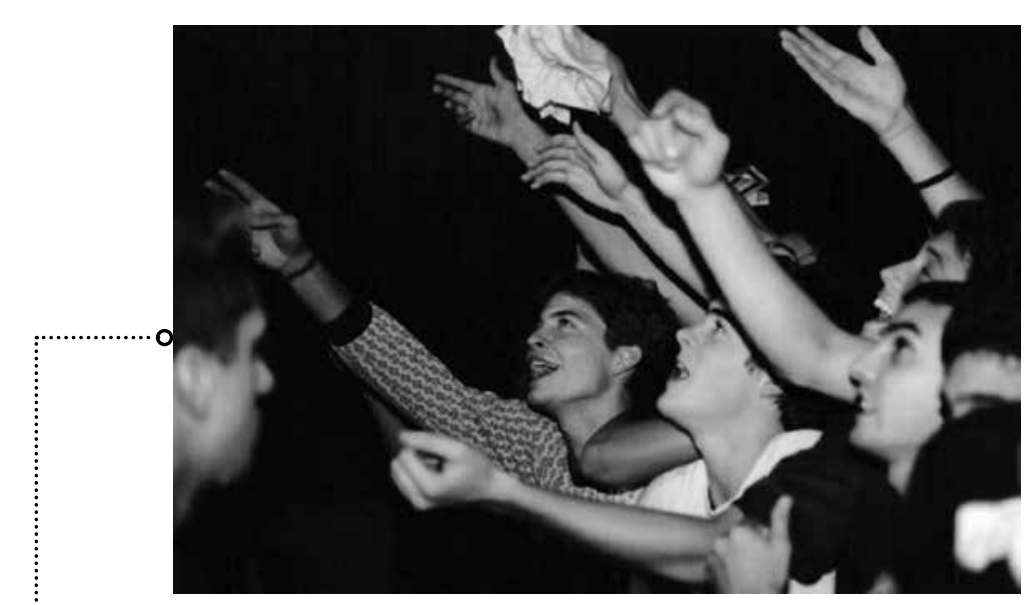

Recitales de Bersuit Vergarabat en Buenos Aires, 1996. Fotografías: Salvador Batalla. en la producción de significantes políticos, concretamente en la oposición al neoliberalismo vigente en los años noventa, así como a la dictadura militar que aconteció en mi país entre 1976 y 1982. Especialmente en el caso de la banda Bersuit Vergarabat, analicé cómo se elaboraba una "estética grotesca", retomando el concepto de Bajtin (1994), en la que un cuerpo hipersexualizado se convertía en soporte de esta resistencia político-cultural (Citro, 1997; 2012).

Un ejemplo fue la canción dedicada al presidente de la nación de aquel momento, en la que el cantante se bajaba los pantalones y movía su cola frente al público, cantando con ritmo de cumbia y sonoridades rockeras:

"rompiendo culo a granel tomaremos el poder"; o también otra canción que, con ritmo de ska, anunciaba "se viene el estallido... de mi guitarra, de tu gobierno también". Este hecho aconteció tres años después, en la crisis político-económica de 2001, que llevó a la renuncia del presidente de aquel entonces, así como de los otros presidentes provisionales que intentaron sucederlo. De hecho, el país llegó a tener cinco diferentes presidentes en el transcurso de diez días.

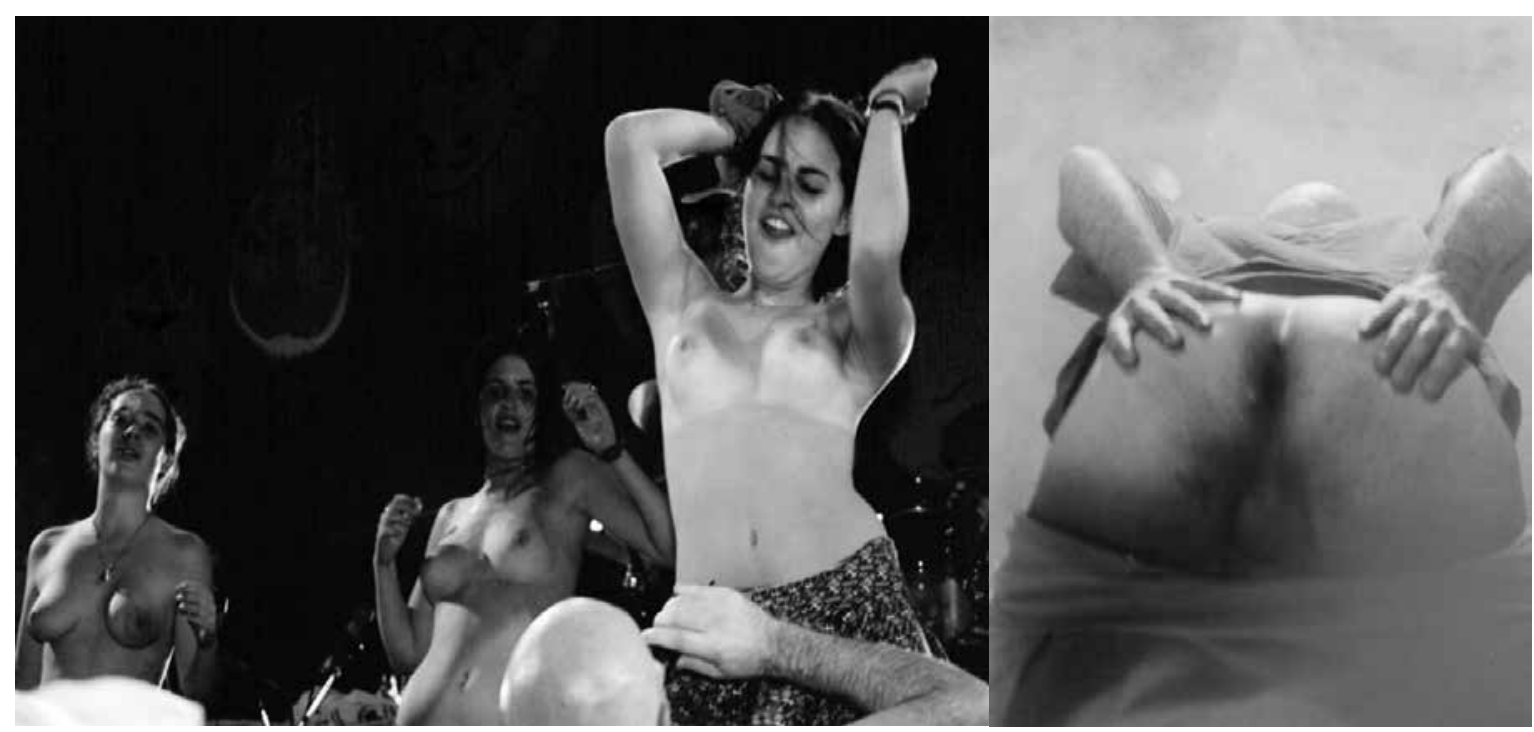

Recitales de Bersuit Vergarabat en Buenos Aires, 1998. Fotografías: Salvador Batalla. Puede verse también el video de "El estallido" de BersuitVergarabat: http://www.youtube.com/watch?v=ydWT6n6VwgA 
En la misma época que realizaba esta etnografía, estrenamos nuestra obra de danza-teatro titulada Trilogía para cuatro ruedas, bailada con "changuitos" o carritos de supermercado, símbolos del consumo en una época en que justamente se multiplicaban los hipermercados y los shoppings en nuestras ciudades. Así, en la primera y segunda parte se expresaba una crítica a la alienación del consumismo capitalista y su impacto en el universo femenino de la vida doméstica, mientras que en la tercera se proponía una posible vía de resistencia subjetiva a partir del juego creativo con el changuito.

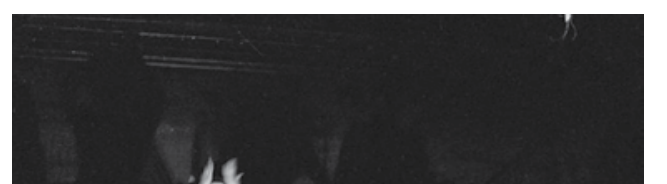

Trilogía para Cuatro Ruedas, Compañía de Andanzas. Dirección: María Lorena Ponce. Centro Cultural Rojas, 1997.

Fotografías: Juan Pablo Ordoñez.

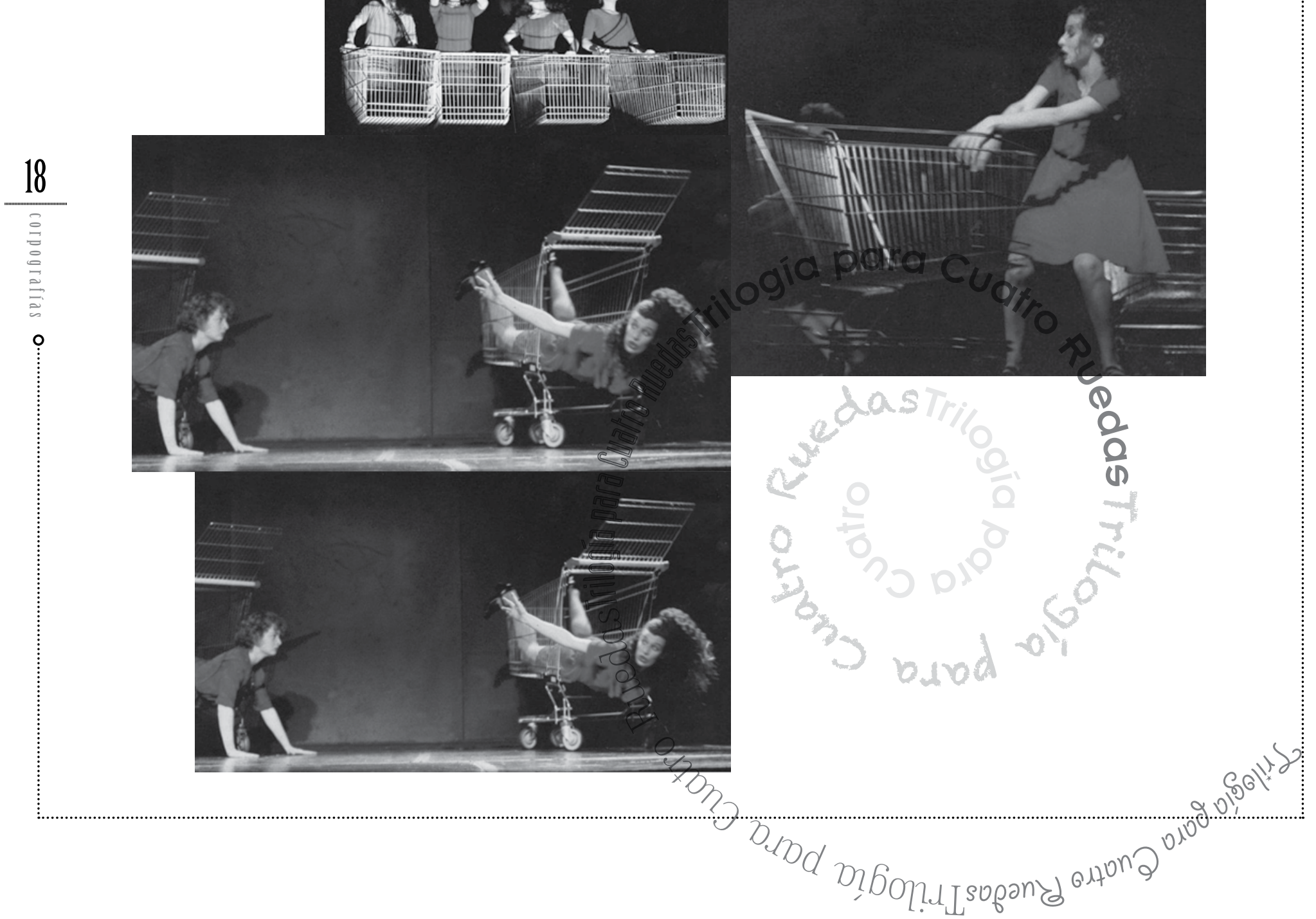


Fue en esta época cuando tuve mi primer encuentro con la fenomenología de Merleau-Ponty y los textos de Bourdieu y Bajtin, los cuales me brindaron las primeras palabras, las primeras redes conceptuales para describir y entender aquellas experiencias que vivenciaba como bailarina y etnógrafa: cómo el cuerpo, a través de sensaciones, gestos y movimientos cotidianos, "tiene su mundo o comprende su mundo sin tener que pasar por unas representaciones, sin subordinarse a una 'función simbólica' u objetivante" (Merleau-Ponty, 1993: 158) y, a la vez, puede también resistir y rebelarse creativamente frente a ese mundo habitual, tal como mostraba Bajtín (1994).

Años más tarde, dentro de la misma compañía, dirigí una obra titulada El cuerpo reb/velado: Retrato de una bailarina dixiana, estrenada en el 2001, pocos meses antes del estallido social de aquel año. La obra reflexionaba en movimiento acerca de las presiones sociales sobre la imagen corporal de la mujer y sobre el mandato de autoconstruirse como objeto de seducción frente a la mirada masculina, inspirada justamente en un cuadro del pintor expresionista alemán Otto Dix, que retrata a una prostituta del período de entreguerras. Así, la obra se iniciaba con una mujer que, con movimientos que remitían a la danza clásica y al vodevil, intentaba seducir a su público ofreciéndole estilizados besos, hasta que su mano comenzaba a reb/velarse y terminaba de-construyendo su propio cuerpo y, entre otros actos significantes, se comía y escupía el lápiz labial con el que se había pintado. Finalmente, venía el encuentro con otras mujeres que operaban como sus álter egos, donde reconstruía una nueva imagen corporal de sí misma.

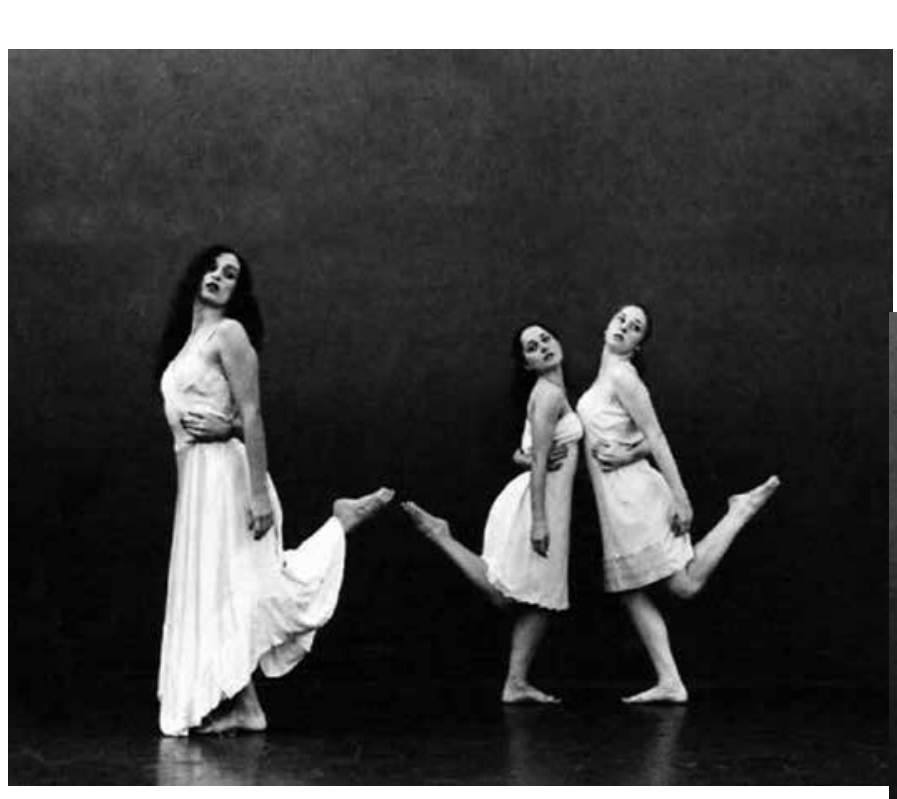

Paralelamente a estas experiencias artísticas, desde 1998 tuve la posibilidad de acceder a una beca de posgrado del estado argentino, otorgada por el Consejo Nacional de Investigaciones Cientíícas y

El cuerpo reb/velado: Retrato de una bailarina dixiana, Compañía de Andanzas, Coreografía: Silvia Citro. Centro Cultural Recoleta, 2001. Fotografías: Salvador Batalla.

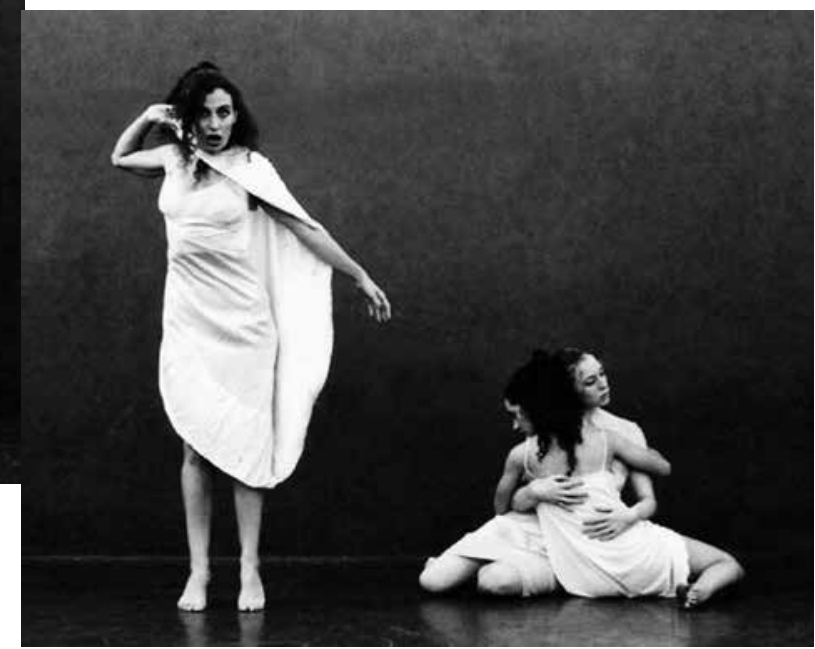


Técnicas (Conicet), para iniciar mis estudios de doctorado en la Universidad de Buenos Aires, en una época en la que en Argentina existían pocas posibilidades de acceder al sistema de becas. En ese momento comencé un estudio más sistemático de Nietzsche y los autores vinculados al posestructuralismo: Foucault, Lacan, Laclau y Butler... Era esa una época en la cual la voluntad de sospecha intelectual aún estaba unida a esos cuerpos reb/velados que encarnábamos en nuestras performances, por eso, creo hoy, fue aquella "una entusiasta síntesis juvenil de teorías y prácticas".

\section{IRRUPCIÓN DE LA CONTRADICCIÓN EXISTENCIAL:}

\section{Afianzamiento intelectual y Represión corporal}

Años más tarde, en el 2003, presenté mi tesis de doctorado, también en la Universidad de Buenos Aires, titulada "Cuerpos significantes. Una etnografía dialéctica con los toba Takshik" y ese mismo año hice mi última actuación en público en la Compañía de Andanzas, con una obra titulada Estampitas Venusinas, dirigida por María Lorena Ponce.

En la tesis doctoral, analicé las corporalidades de los tobas, un grupo indígena del noreste argentino que, si bien vivía en condiciones de pobreza, también tenía la peculiaridad de haber creado su propio movimiento de iglesias evangélicas aborígenes, en las que la música y la danza adquirían un lugar central, así como una gran riqueza cultural, por su dinamismo y diversidad. Cabe destacar que la mayor parte de mi etnografía fue efectuada entre 1998 y 2002, los peores años de la crisis del modelo neoliberal en Argentina.

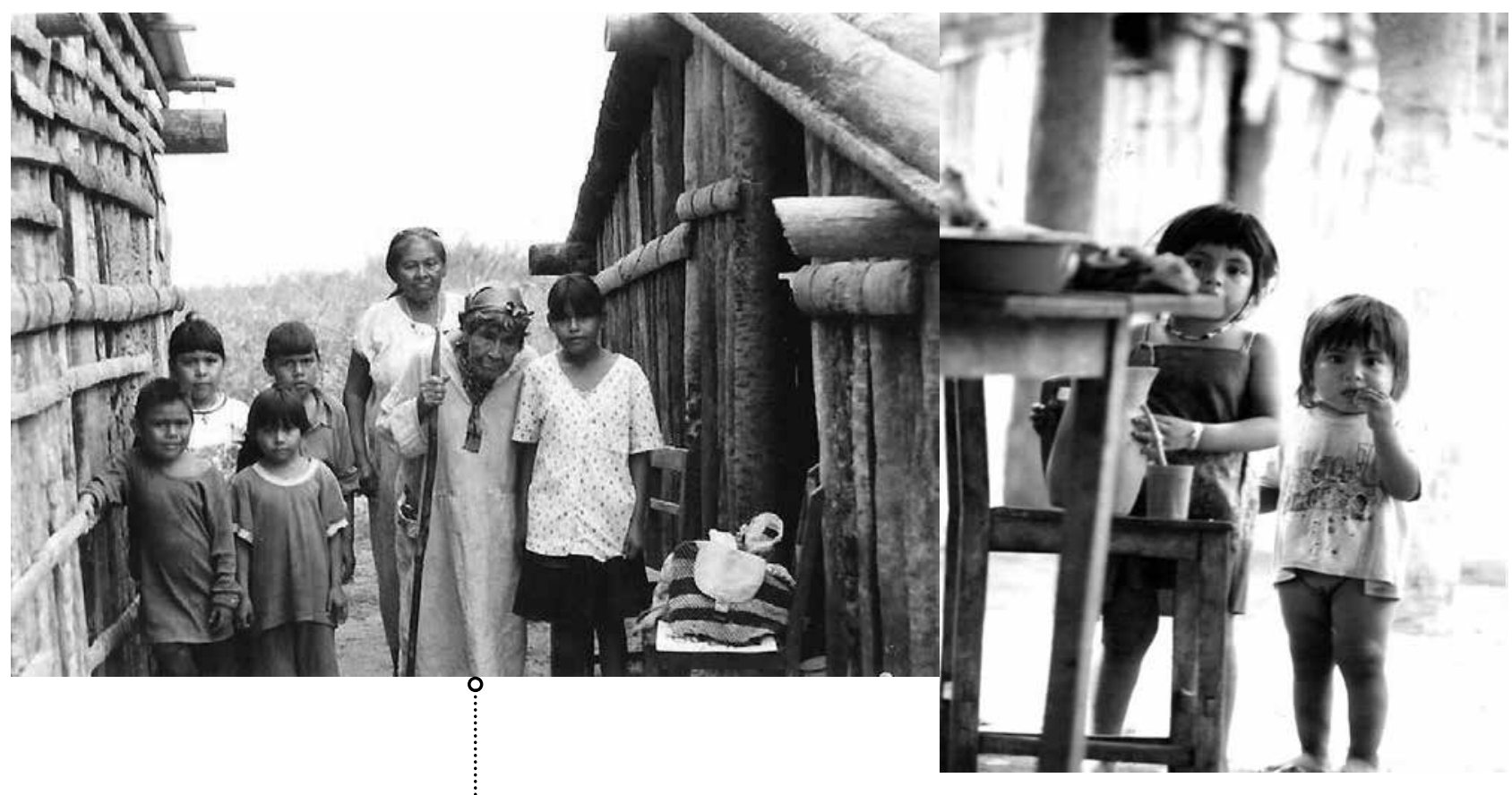




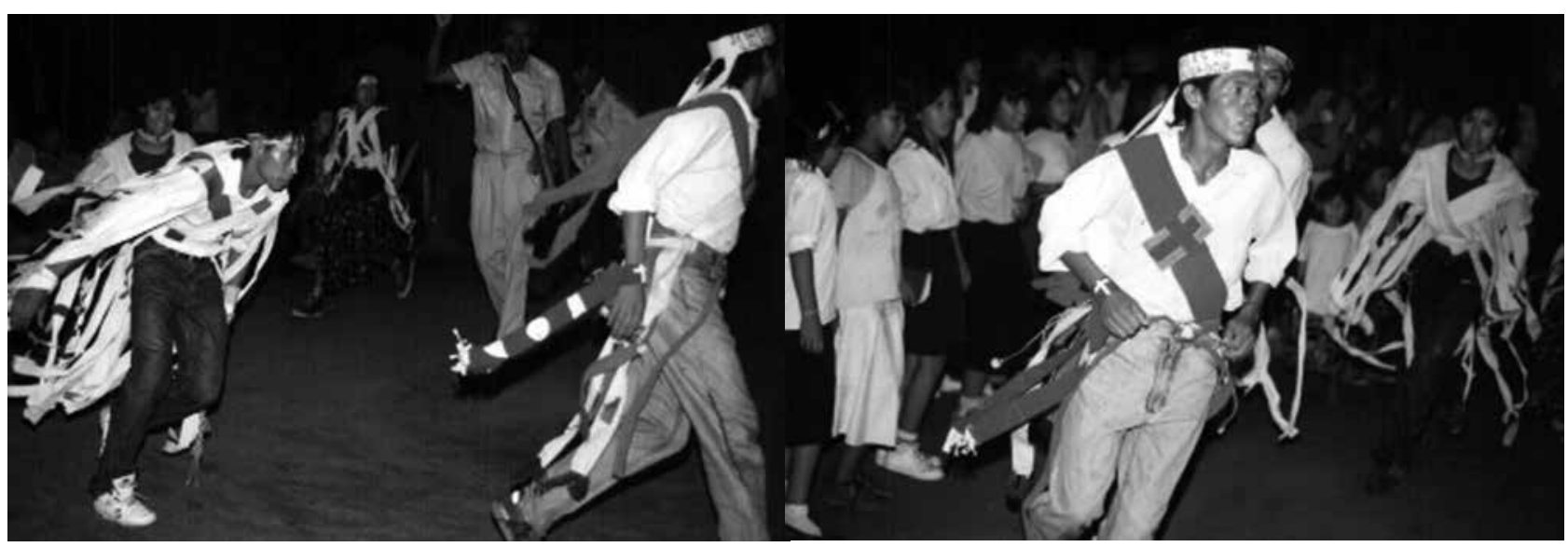

- Comunidades aborígenes tobas La Primavera y Misión Tacaaglé, en Formosa, Argentina, 1998. Fotografías: Salvador Batalla.

En el caso de la obra de danza de aquella época, representábamos con música de Bach a Gertrudis y Edelma, dos hermanas bastante reprimidas en sus corporalidades, entre otras cuestiones, por la religión. Si bien el hecho de que abandonara la danza luego de esta obra, lo podría vincular en parte con mi edad -pues tanto la danza como el deporte han alcanzado un grado de tecnificación y rendimiento que hace que la vida útil de los cuerpos en estas disciplinas se acorte cada vez más-, fundamentalmente lo que me sucedió es que el mundo académico fue tomando cada vez más tiempo y reduciendo así el que le podía dedicar al movimiento corporal expresivo. Así, mi cuerpo se iba reprimiendo, tal como les sucedía a los cuerpos de Gertudris y Edelma, aunque en mi caso por razones profesionales. Justamente, diría que luego de mi doctorado las cosas empezaron a marchar bien en lo académico, aunque no sin esfuerzo y cierto estrés.

Así, en 2004 conformamos nuestro equipo de investigación en antropología del cuerpo y la performance y organizamos el primer simposio sobre cuerpo en los Congresos Argentinos de Antropología Social, así como los primeros seminarios universitarios sobre el tema. También obtuvimos subsidios para investigaciones colectivas, y la mayoría de los graduados de nuestro equipo consiguieron becas para realizar sus estudios de posgrado. Los proyectos del equipo focalizaron en la creciente difusión de diversas ofertas dirigidas al cuerpo, que abarcan distintas técnicas corporales, rituales, prácticas de cuidado y salud de los cuerpos provenientes de distintas tradiciones histórico-culturales, muchas veces fragmentadas e hibridadas entre sí, así como de tecnologías médicas, farmacéuticas, deportivas y estéticas occidentales. Como veremos, la posibilidad de trabajo grupal nos permitió indagar en el impacto que estos nuevos consumos corporales tenían en las prácticas de subjetivación, comenzando a realizar estudios comparativos, especialmente en lo que hace a la actual reapropiación de tradiciones corporales de orígenes orientales, afro y amerindios, entre 
las clases medias de nuestras ciudades (Citro, Aschieri y Mennnelli, 2011).

Es importante señalar que este afianzamiento académico de nuestro equipo se dio en una época en la que en Argentina comenzaba un proceso de cambio político-económico con el abandono del modelo neoliberal y de una mayor presencia del Estado, que entre otras cuestiones implicó creciente apoyo al trabajo científico. Los últimos años de la década del noventa y la crisis del 2001 habían generado en la memoria colectiva y en la mía propia sensaciones de temor a la inestabilidad económica y la pérdida de trabajo, lo que probablemente influyó en que algunos jóvenes investigadores del Conicet sintiéramos que debíamos "aprovechar" aquella nueva coyuntura económica, político y cultural que se estaba gestando en el país y emprendiéramos entonces una intensa carrera académica. Pero cuando uno empieza a correr, también puede tropezarse, caer y quedar inmovilizado por algún tiempo.

\section{Del CUERPO SOPORTE A LA IMPOSIBILIDAD DE MOVIMIENTOS}

A medida que con nuestro equipo nos consolidábamos en el campo académico, mejorábamos nuestra situación económica, y personalmente me alejaba de la danza-teatro, uno de los efectos colaterales de estos cambios fue el crecimiento de una hernia de disco entre la cuarta y quinta vértebra lumbar, que me dejó literalmen-

Gertrudis y Edelma, Compañía de Andanzas. Dirección: María Lorena Ponce. Buenos Aires Danza Independiente. Instituto Universitario Nacional de Arte, 2003. Fotografías: Juan Pablo Ordoñez.

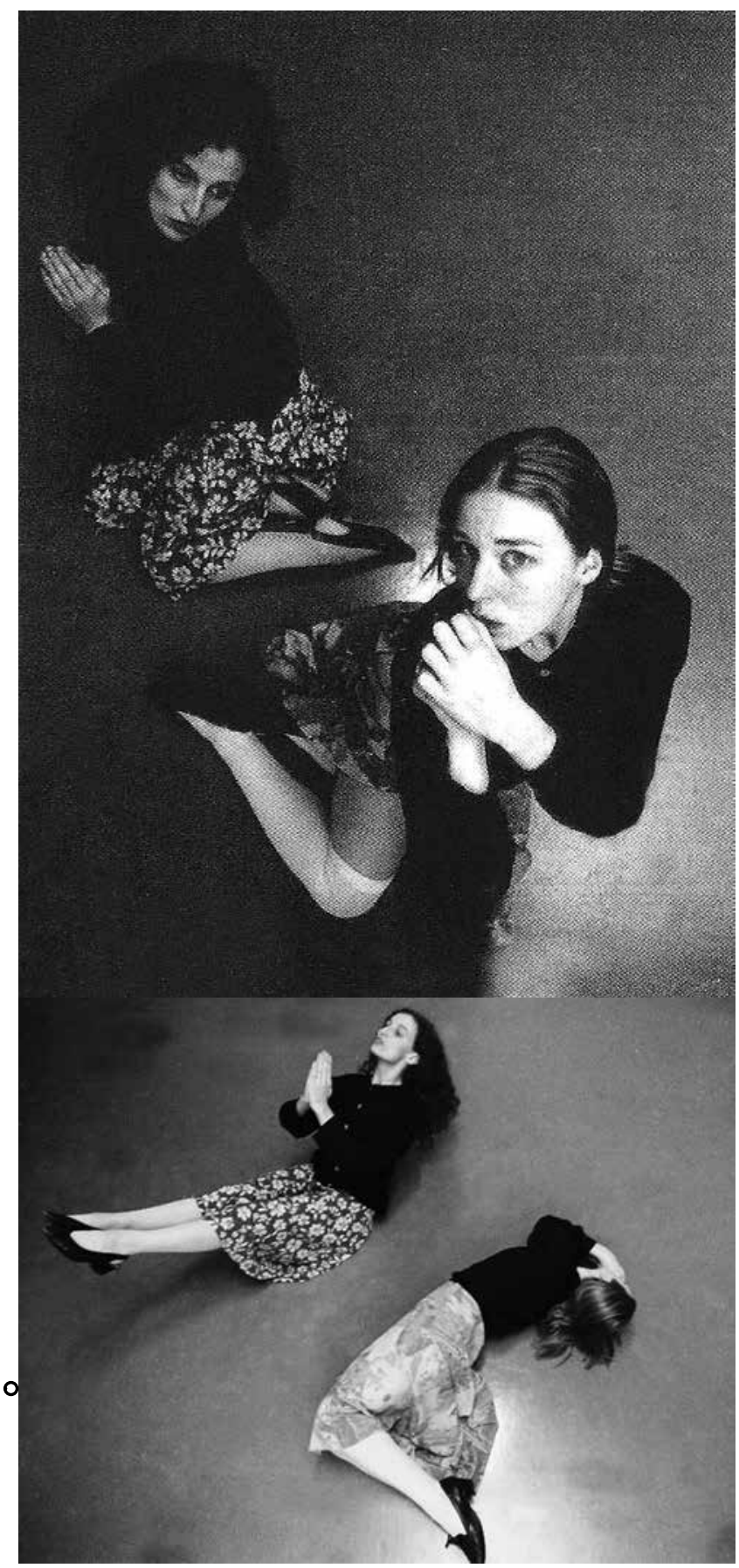


te inmovilizada, pues el dolor me impedía caminar. El origen de este tipo de hernias suele permanecer muchas veces incierto o confuso para el discurso biomédico; en mi caso, lo atribuí principalmente a las largas horas que comencé a pasar inmovilizada, sentada frente a la computadora o un libro, así también como a algunas otras problemáticas afectivas familiares, como las separaciones. En Buenos Aires, muchas mujeres profesionales de clase media de mi generación suelen pasar algunos años por terapias psicoanalíticas, por lo cual las interpretaciones sobre somatizaciones de conflictos intersubjetivos suelen ser bastante comunes, pero en mi caso sumaba también un muy concreto y material cambio de hábitos corporales². Así, luego de probar kinesiología, ozonoterapia, psicoanálisis y varias técnicas de origen oriental que se ofertan en nuestras ciudades latinoamericanas, como reiki, acupuntura y tai chi, no encontré otra opción que operarme en 2008. Las huellas de aquel cuerpo más inmóvil, que ya no bailaba y que fue el soporte del afianzamiento académico, se convirtieron en estas pequeñas pero dolorosas heridas que la operación quirúrgica intentó remover.

No obstante, estas heridas pudieron ser sublimadas con cierto humor, al convertirse en soporte de una nueva obra, esta vez no dancística sino fotográfica, en el trabajo que efectuamos con Salvador Batalla. Incluso tiempo después esta obra se convirtió en el arte de tapa del disco compacto Fisura expuesta, de Juan Subirá, uno de los integrantes de la Bersuit, la banda de rock de mi primera etnografía.

Si bien la operación había sido exitosa en términos médicos, al lograr cortar la hernia que aprisionaba el nervio ciático, a los pocos meses volvió a salir otra hernia, en el mismo lugar, doblegándome y deteniéndome nuevamente. Además, a los pocos meses viví una situación familiar muy dolorosa con la muerte de mi hermano y su familia en un accidente automovilístico, y esa experiencia hizo

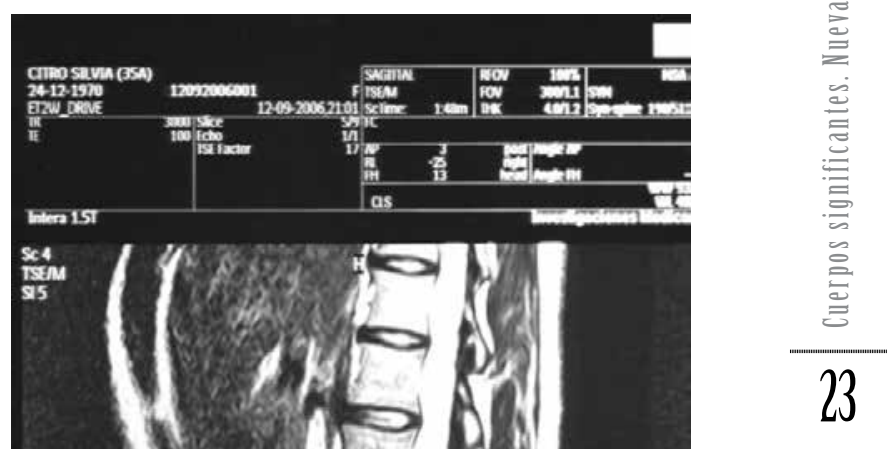
que mi cuerpo olvidara el dolor físico de la hernia y se irguiera nuevamente, para hacerme cargo de mi sobrino, único sobreviviente.

2 En la época de escritura de la tesis, recuerdo un sueño que tuve: me desplazaba por las calles de la ciudad sentada en la silla con rueditas de mi escritorio de trabajo, y pese a mi sorpresa y los intentos de despegarme de la silla durante el mismo sueño, no lo podía hacer. 


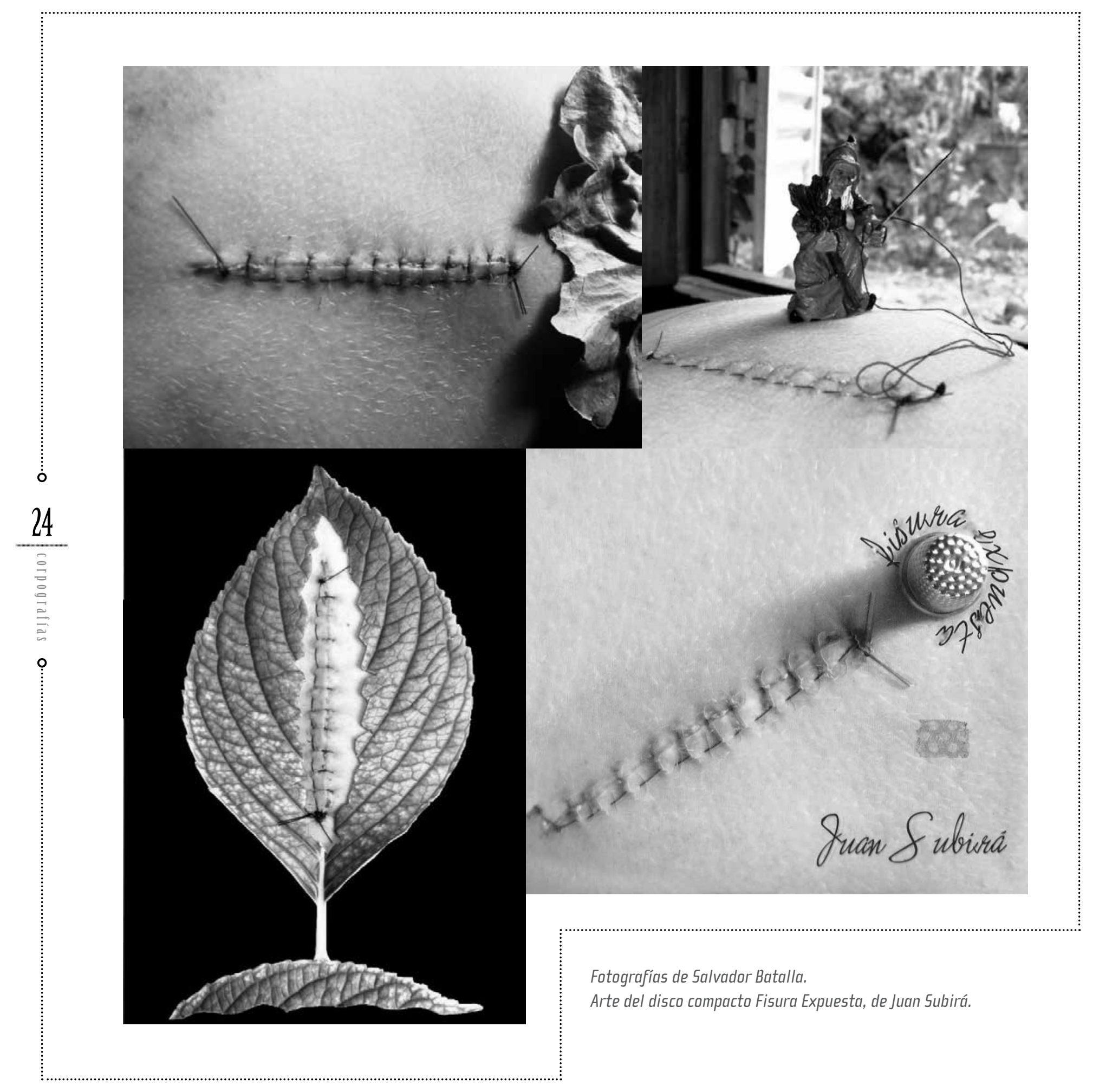




\section{Hacia un nuevo inTento de síntesis colectiva}

Así como el origen de la hernia lo atribuí a la conjugación de técnicas corporales patológicas, dinámicas afectivas familiares dolorosas y cierto estrés profesional posterior a la crisis de 2001, creo que la cura también fue posible por la posibilidad de empezar a construir una nueva síntesis, más placentera, entre las experiencias corporales, afectivas familiares y profesionales, en un contexto político cultural favorable -en tanto se iba acercando, aunque no sin contradicciones, a ciertos cambios que, desde la recuperación de la democracia en los años ochenta, algunos veníamos reclamando-. Reseñaré brevemente estos últimos recorridos.

Paralelamente al proceso afectivo de encarnar una maternidad adoptiva, comencé a tomar clases de elongación y biomecánica que me devolvieron progresivamente el control de mi cuerpo. Asimismo, experimenté un renovado impulso a la escritura y logré transformar mi tesis doctoral en un libro: Cuerpos significantes. Travesías de una etnografía dialéctica (2009). Y en los años subsiguientes publicamos dos compilaciones: Cuerpos plurales. Antropología de y desde los cuerpos (2010) y Cuerpos en movimiento. Antropología de y desde las danzas (2012). Ambos libros incluían una reseña inicial de los principales enfoques teórico metodológicos y traducciones inéditas de autores fundamentales en ambos campos, así como investigaciones específicas, efectuadas por miembros de nuestro equipo y de otras universidades de Argentina.

Pienso hoy que las fotos de las tapas de aquellos libros, realizadas con Salvador Batalla, al enfatizar en el movimiento de los pies y las manos, metafóricamente expresaban algo de esa pulsión vital que nos lleva a seguir caminando
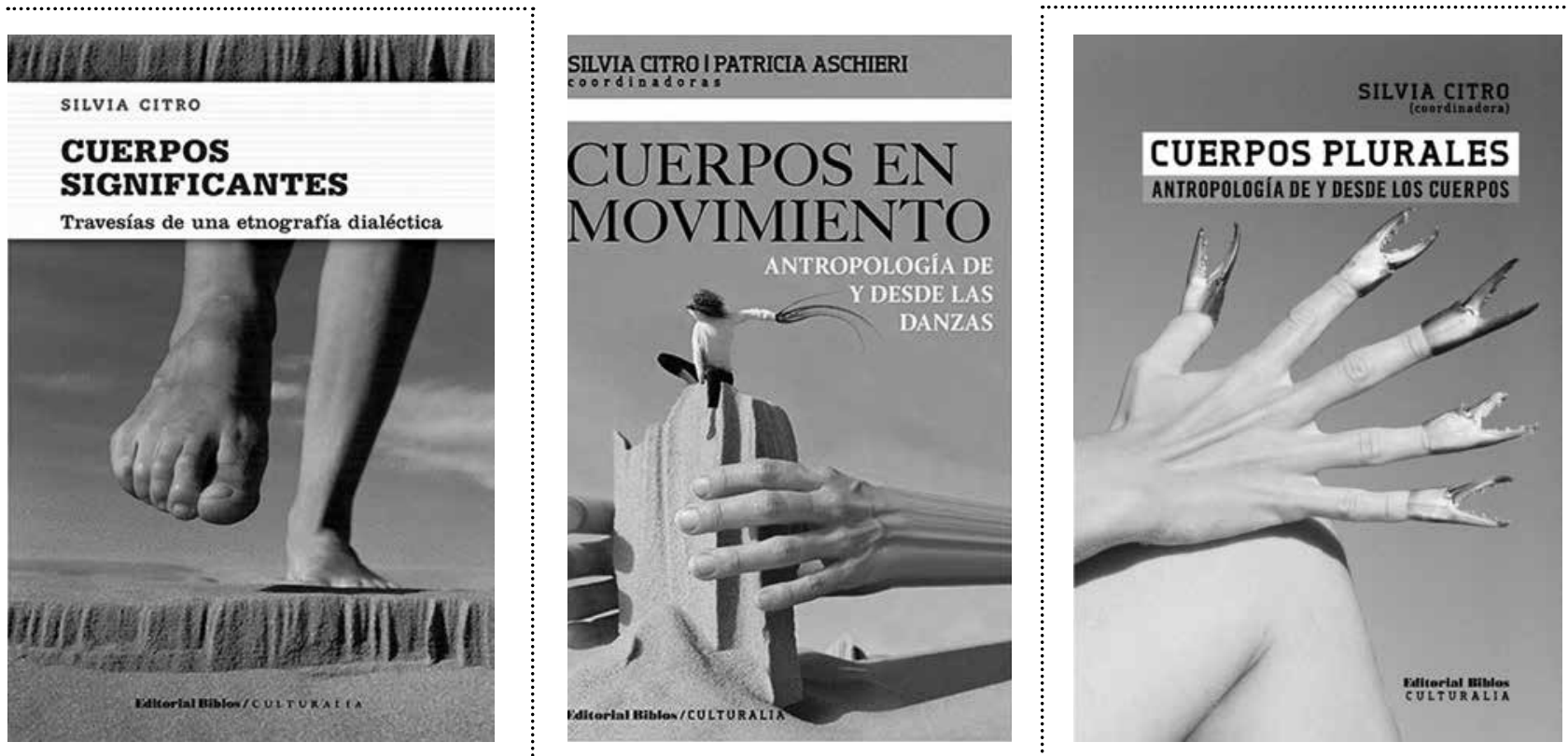
y construyendo, a pesar de las adversidades y resistencias. Y como parte de este proceso de reconstrucción, también volví a danzar, pero danza butoh, una danza de improvisación de origen japonés en la que ya no interesa tanto el cuerpo tecnificado, joven y vital (de hecho, fue creada y bailada por dos performers de edad avanzada), sino que explora los devenires y transformaciones del cuerpo propio, tomando como tema, entre otras cuestiones, el tránsito entre opuestos, como la vida y la muerte, el placer y el dolor, lo humano y lo natural, lo femenino y lo masculino, lo consciente y lo inconsciente (Aschieri, 2012). Me inicié en esta danza con Patricia Aschieri, antropóloga y performer que ahora cocoordina nuestro equipo y con la cual coeditamos el libro Cuerpos en movimiento. Así, luego de varios años, empezamos a transitar un nuevo momento de provisoria síntesis entre algunas contradicciones existenciales y pusimos, una vez más, nuestros cuerpos en movimiento.

A partir de 2012 con el equipo también hicimos un pequeño "salto utópico" que, como todo salto -lo reconocemostrae el peligro de la "caída” y de quedar "mal parados", intentando revincular aquellos movimientos y discursos, teorías y prácticas que diez años de profesionalización académica escindieron. Nos propusimos entonces construir una antropología de y desde los cuerpos, de y desde los movimientos, pero ya no solamente en nuestros modos prácticos de hacer etnografía, sino también en las formas en que reflexionamos y difundimos los resultados de nuestras investigaciones. De este modo, buscamos incentivar nuevas modalidades de trabajo académico, capaces de construir síntesis dialécticas colectivas que sean superadoras de las dicotomías cuerpo-mente ligadas al individualismo heredado de la modernidad occidental. Y, como parte de este proceso, también tratamos de profundizar y extender el trabajo colectivo, impulsando redes nacionales y luego latinoamericanas, porque, como la historia nos demuestra, solo con la organización colectiva es que podemos iniciar cualquier movimiento hacia las utopías. Así fue que en 2012 organizamos el Primer Encuentro Latinoamericano de Investigadores sobre Cuerpos y Corporalidades en las Culturas, en la Universidad Nacional de Rosario, a partir del trabajo en red con colegas de Argentina de las universidades de Rosario, La Plata y Buenos Aires, y latinoamericanos, como Zandra Pedraza de Colombia, Elsa Muñiz de México, Jose Bizerril de Brasil, Liuba Kogan de Perú, con los que conformamos una red de trabajo latinoamericana. En este encuentro, se desarrollaron las ponencias orales en 16 grupos de trabajo, que contaron con un total de 600 inscritos entre ponentes y asistentes, se expusieron pósters y, al cierre de cada grupo, se hicieron prácticas de trabajo corporal en formato de "taller", con la intención de efectuar una elaboración, desde la propia corporeidad, de algunos de los principales temas y reflexiones que surgieron durante las ponencias y discusiones. También vinculados a cada grupo de trabajo hubo performances que consistían en "intervenciones" artísticas en los espacios públicos de la Facultad en que transcurrió el encuentro. El cierre incluyó, además de las conclusiones de cada grupo de trabajo, una performance colectiva en la que confluyeron ponentes, coordinadores y asistentes. En la página Web de la Red ${ }^{3}$ puede verse el video del encuentro e incluimos aquí también algunas fotos.

En línea: http://red.antropologiadelcuerpo.com/ 


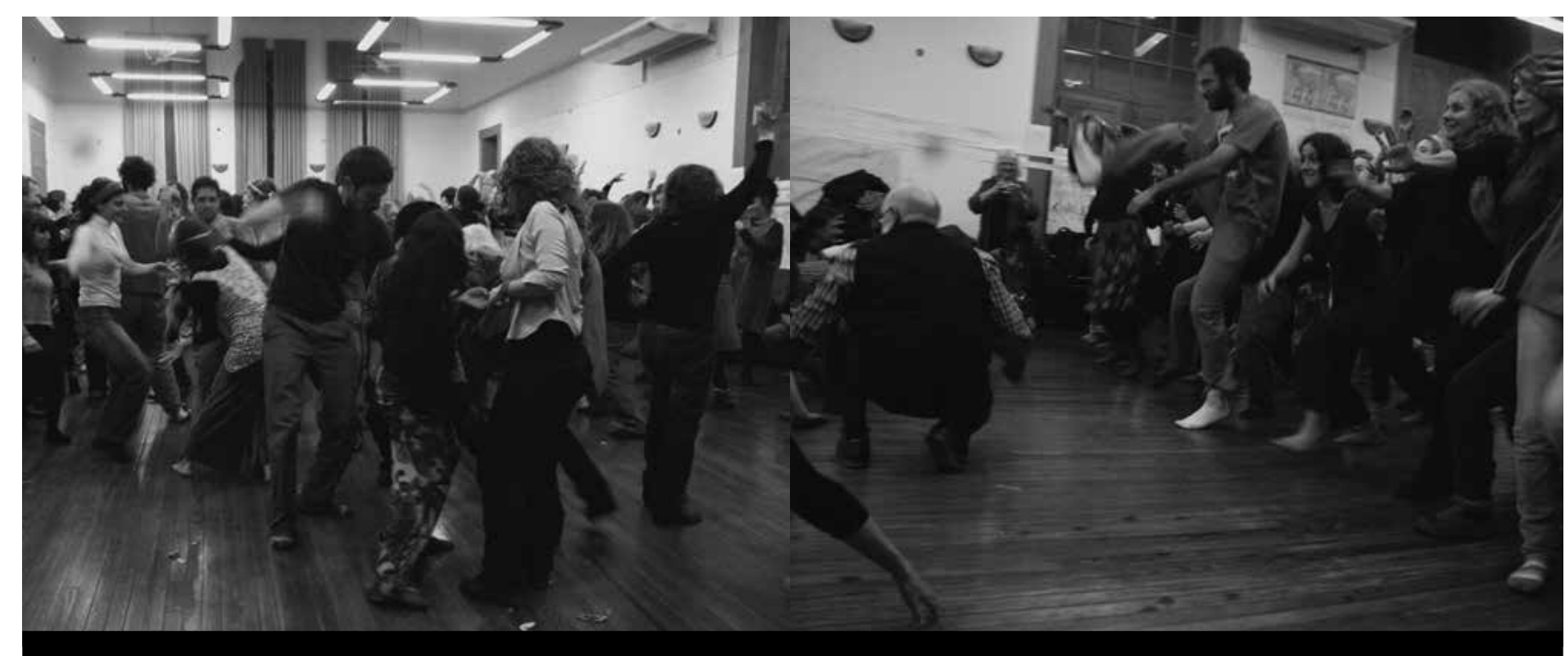

Performance final, Primer Encuentro Latinoamericano de Investigadores sobre Cuerpos y Corporalidades en las Culturas, Universidad Nacional de Rosario. Fotos: Giulia Ricciotti.

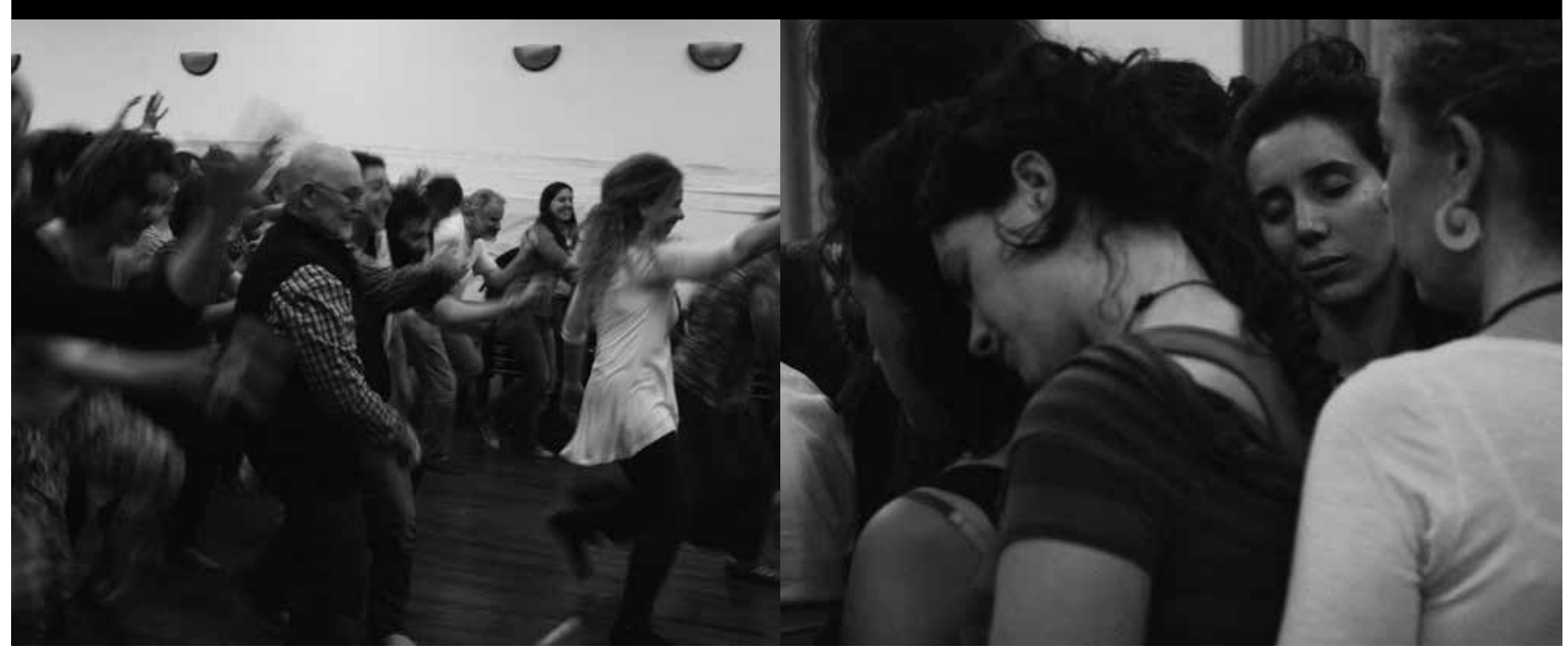

Finalmente, a partir de 2013, Ilevamos este mismo tipo de experiencias teórico-prácticas al campo de la docencia universitaria, combinando las lecturas, discusiones y reflexiones discursivas con experiencias que apelan a las percepciones sensoriales, la gestualidad y el movimiento corporal, así como a otras experiencias sonoras y visuales. 


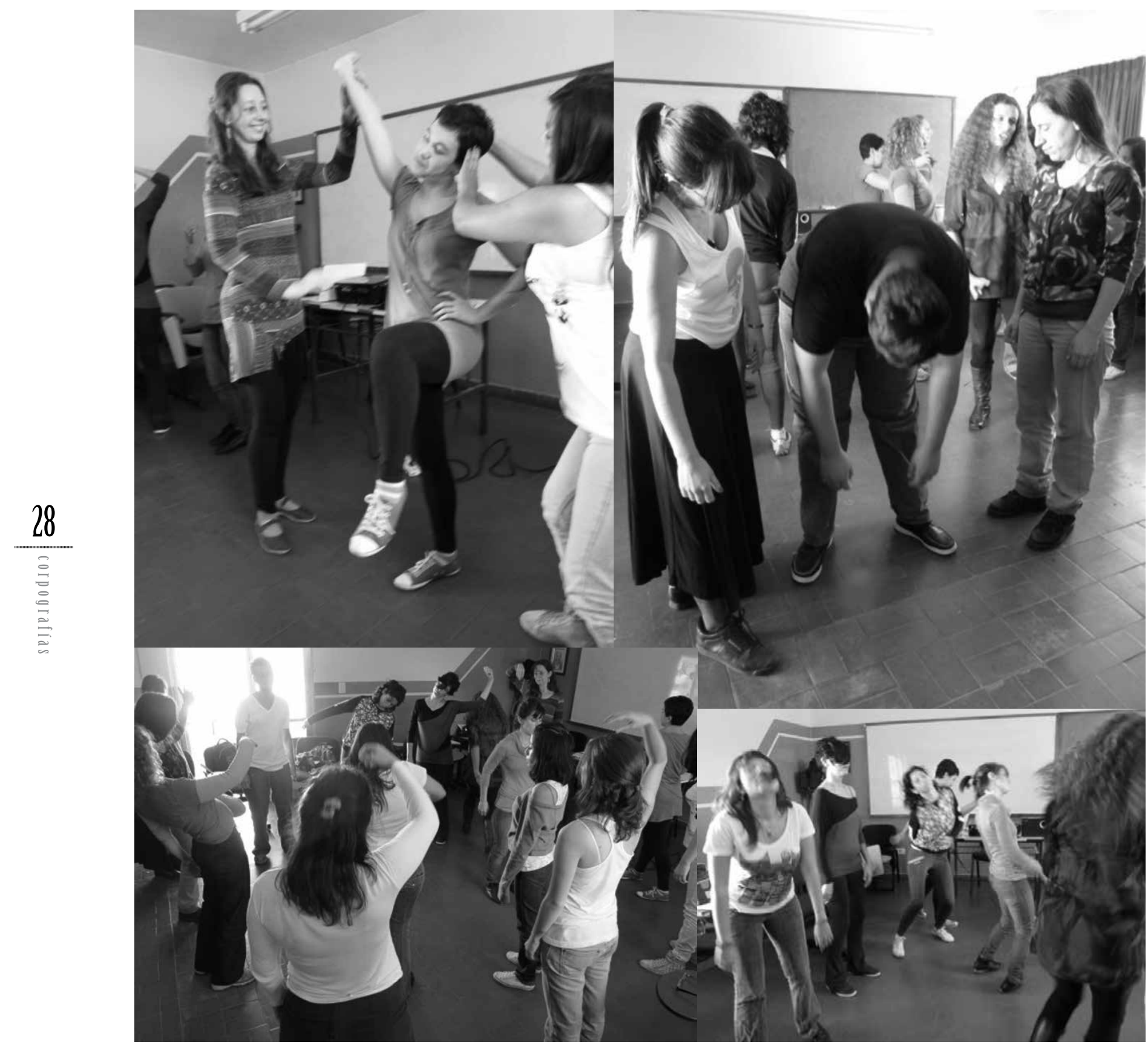

Curso de Posgrado en Antropología del Cuerpo, Universidad Nacional de Salta. Clase: Cuerpo y poder - Foucault: disciplinas y tecnolo gías del yo / Ser movido por... y moverse a sí mismo. 


\section{Desafíos teórico-metodológicos actuales}

A partir de este recorrido genealógico, quisiera destacar al menos tres desafíos teórico-metodológicos que surgen en el estudio de la corporalidad y que hemos venido compartiendo con nuestro equipo y también con otros colegas latinoamericanos con los que nos fuimos vinculando durante esta última década. En primer lugar, al retratar estas escenas que combinaron referencias intelectuales, artísticas, médicas, afectivas y políticas sobre la corporalidad, intenté mostrar cómo nuestras corporalidades y nuestras producciones intelectuales sobre el cuerpo, son el resultado de un complejo entramado de materialidades biológicas, tecnologías, procesos psicológicos intersubjetivos, históricos y político-culturales que entrelazan sensaciones, movimientos, afectividades, imágenes, representaciones y discursos. Por tanto, el desafío ante tal complejidad consiste en evitar caer en un reduccionismo del cuerpo que lo someta a la mirada unilateral de una sola disciplina; de ahí emerge, creemos, la tendencia a una mayor interdisciplinariedad, que se advierte en los últimos años en los estudios sobre corporalidades.

No obstante, quisiera recordar que este problema estaba ya presente en los inicios de la preocupación socioantropológica por el cuerpo, pues ya Marcel Mauss (1979: 340), en su famosa y varias veces citada conferencia de 1936 sobre las "técnicas del cuerpo", nos decía que no se puede llegar a tener un punto de vista claro sobre estos hechos, si no se tiene en cuenta una triple consideración: "ya sea física o mecánica, como puede serlo una teoría anatómica o fisiológica, sociológica y psicológica, lo que hace falta es un triple punto de vista: el del ser humano total". Si bien no ahondaremos en este tema, veremos que, en nuestro equipo, por ejemplo, hemos venido dialogando con la filosofía, la historia, el arte, la psicología y, especialmente, con el psicoanálisis, y más recientemente con la biología y las neurociencias (Citro, Lucio y Puglisi, en prensa; [itro, en prensa]; asimismo, la experiencia de organización de simposios y congresos con otros colegas latinoamericanos también nos reveló tendencias similares en otros grupos de investigación.

El segundo desafío que enfrentamos, ya más específicamente en el campo de las ciencias sociales y humanas, es el de mostrar cómo esa corporalidad compleja es fruto de historias y contextos afectivo-familiares y socioculturales que se inscriben poderosamente en nuestra carne y la delimita a partir de múltiples, reiteradas y sutiles relaciones a la vez que esa misma carne es sede de nuestra agencia, creatividad, singularidad subjetiva, e incluso de nuestra resistencia político cultural. Esto nos enfrenta a una paradoja: cómo analizar estas complejas dimensiones de un cuerpo que es indudablemente objeto de relaciones de poder y, a la vez, encarnación de nuestra agencia. Y aquí, una vez más, intentando evitar miradas reduccionistas, nuestras investigaciones en este punto buscaron articular diferentes abordajes teórico-metodológicos en una perspectiva dialéctica que, como veremos, confronta ciertos abordajes semióticos y posestructuralistas con los fenomenológicos.

Finalmente, el tercer desafío se vincula a nuestra doble trayectoria en el campo académico intelectual y de las artes de la performance, que con el tiempo también descubrimos que compartían otros colegas, especialmente los de 


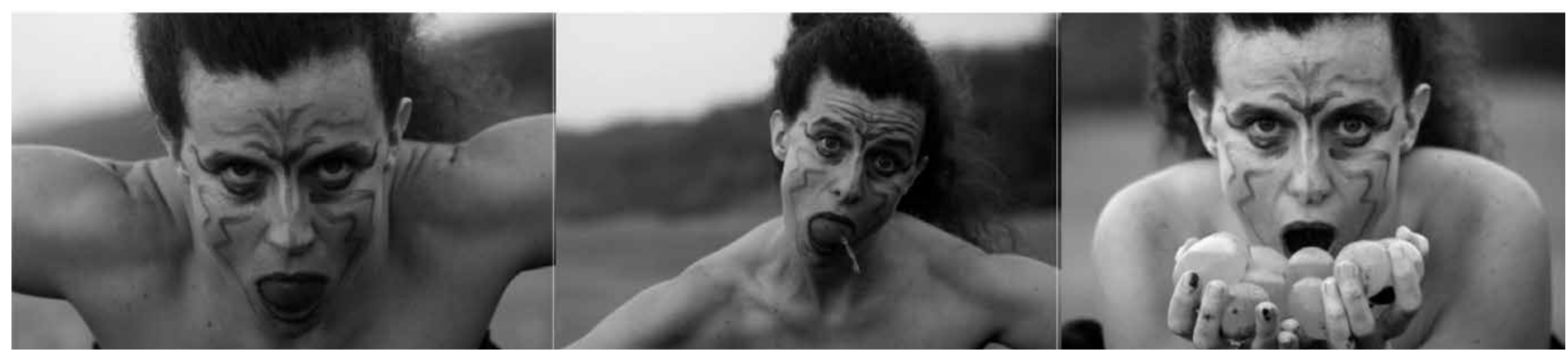

las generaciones más jóvenes que se acercan a estas temáticas. Ya Nietzsche, nuevamente, oponiéndose a los hábitos hegemónicos del racionalismo cartesiano, en la Gaya ciencia sostenía que él no era "de los que tienen ideas entre los libros", pues estaba "acostumbrado a pensar al aire libre, andando, saltando, escalando, bailando" (1995: 249). No obstante, las prácticas institucionales académicas lejos están aún de estimular esos otros modos posibles del pensar; por eso, como vimos, nuestro compromiso actual se orienta a ensayar nuevos modos de integrar teorías y praxis corporales, expresiones intelectuales y estéticas. En los próximos apartados profundizaremos entonces sobre estos últimos desafíos y tensiones y veremos cómo nos condujeron a plantear propuestas dialécticas.

\section{Corporalidades en perspectiva dialéctica: Hacia una síntesis ENTRE ACERCAMIENTO FENOMENOLÓGICO Y DISTANCIAMIENTO GENEALÓGICO}

Como pudo apreciarse, mi presentación inicial refirió a contradicciones, tensiones y momentos de provisorias síntesis y a que fueron justamente estas experiencias intersubjetivas y etnográficas las que me llevaron a percibir la realidad y el cuerpo dialécticamente. Asimismo, vimos cómo estas experiencias transcurrieron en un contexto geopolítico e histórico sumamente cambiante y contradictorio, por lo cual también me condujeron a percibir la realidad social de manera dialéctica. Sintéticamente: mi educación primaria fue durante la dictadura militar iniciada en 1976, la secundaria durante la euforia de la democracia recuperada en 1983, la formación universitaria con el auge del neoliberalismo de los años noventa y mi desempeño profesional transcurrió entre la debacle de ese modelo, que condujo a la crisis del 2001, y el creciente apoyo a la actividad científica con la gestión iniciada en 2003.

En términos corporales, una de las contradicciones más persistentes se dio en mi experiencia como bailarina y como académica. La primera involucraba un compromiso sensorial y emotivo intenso de mi cuerpo en el mundo, en el cual los movimientos se convertían en la principal fuente de agencia; la segunda, en cambio -especialmente durante las 
largas horas sentada leyendo o escribiendo en frente de una computadora- implicaba un uso de mi cuerpo más parcial, desapasionado y repetitivo, como una especie de medio técnico del pensamiento discursivo que guiaba mis acciones. Sin embargo, sentía que ninguno de los dos mundos por sí solo me alcanzaba y siempre necesité transitar por ambos.

De manera más o menos similar, ya desde mi primera etnografía comencé a advertir tensiones semejantes. Por ejemplo, en el caso de los jóvenes seguidores de las bandas de rock, entre los intentos de disciplinamiento que vivían en los ámbitos familiares y sobre todo en las escuelas y en los usos expresivos de la gestualidad y el movimiento en los recitales, pues, como me explicaba un joven practicante del pogo, el recital era para ellos como "salirse un poco de la sociedad". No obstante, también analicé cómo esas prácticas transgresoras estaban ritualmente pautadas y, por ejemplo, muchas veces reproducían estereotipos en torno a las desigualdades de género (Citro, 1997; 2012).

Posteriormente, también en la etnografía con los tobas, emergió un fuerte contraste entre los cuerpos dinámicos y poderosos de las danzas y cantos rituales, que les permitían por ejemplo adquirir fortaleza y curarse de enfermedades, y los cuerpos más disciplinados de las lecturas bíblicas y los discursos de pastores y predicadores. De hecho, mi investigación se hizo en un período de fuertes conflictos entre las iglesias, porque mientras algunas alentaban las danzas de los jóvenes, otras las condenaban y trataban de desalentarlas o incluso prohibirlas. Asimismo, otras de las tensiones estaba en que mientras estos cuerpos en danza se empoderaban durante sus rituales, luego en su vida cotidiana seguían padeciendo las consecuencias de la desigualdad económica y la dependencia, por ejemplo, a partir de un clientelismo político que se articulaba ideológicamente con la peculiar pobreza, paciencia y obediencia que propicia el discurso evangélico vigente entre los tobas ([itro, 2003; 2009).

Finalmente, en las investigaciones colectivas que iniciamos con nuestro equipo en 2006 también advertimos cómo, en el escenario económico-político-cultural creado por los procesos de globalización y multiculturalismo, la difusión de diversas prácticas corporales tiende a ampliar las posibilidades de autoconstrucción del propio cuerpo, pues, como sostiene Shilling (1993), este pasa a concebirse como un "proyecto" que reclama trabajo, mejoras, modificaciones. No obstante, Lipovetsky (1986) también señala que, si bien este nuevo escenario de consumo promueve un nuevo narcisismo a través de la "personalización del cuerpo", implica también un "narcisismo dirigido", en cuanto cumple una Función de normalización: el medio de "ser verdaderamente uno mismo" es tener siempre un cuerpo "joven, esbelto, dinámico, bello y saludable", según las normas que el mercado va imponiendo. De este modo, se instalan otras sutiles formas de dominación en las que la antigua "norma dirigista o autoritaria" es sustituida por la "norma indicativa, flexible" que opera por seducción en el mercado de consumo. Justamente muchas de las etnografías del equipo nos permitieron advertir las tensiones entre estos procesos de personalización y a la vez normalización de los cuerpos, en los que se ponen en juego tanto la agencia como la reproducción, las prácticas de empoderamiento y las de disciplinamiento, a partir de sutiles y nuevas modalidades de ejercicio del poder (Citro, Aschieri y Menneli, 2011). 
En suma, fue la apertura etnográfica -y también intersubjetiva, sensorio-emotiva y política- a estas diversas experiencias la que nos condujo a indagar en diferentes teorías, para comprender mejor una dinámica social que percibimos compleja y contradictoria. Así, la preocupación por entender cómo el cuerpo es objeto de técnicas y representaciones culturales, habitus, discursos, normas y disciplinas nos llevó a los trabajos de Foucault, Bourdieu y Butler, los cuales tuvieron un importante impacto en los estudios antropológicos sobre el cuerpo, especialmente a partir de los años ochenta. No obstante, desde nuestra misma experiencia, la materialidad del cuerpo no podía ser entendida solo como un "objeto pasivo" de las prácticas y representaciones socioculturales que lo conforman, pues también involucra una dimensión productiva significante, que juega un rol activo y transformador en las prácticas sociales. En consecuencia, este interés en las corporalidades como constituyentes de las subjetividades y prácticas culturales nos condujo a la fenomenología de Merleau-Ponty, que tuvo una gran influencia en la antropología a partir de los años noventa, especialmente en los estudios de Jackson (1983) y [sordas (1993), justamente los autores que tradujimos al español en nuestra primera compilación sobre antropología del cuerpo. Así, desde mis primeras investigaciones (Citro 1997; 1999) intenté metodologías que involucraran estos dos tipos de aproximaciones. Tiempo después encontré que autores como Lock y Sheeper Huges (1987), Crossley (1996) y Alcoff (2000) proponían combinaciones similares, aunque no necesariamente dentro de un marco explícitamente dialéctico. Fue especialmente [sordas (1994: 12) quién afirmó que las teorías del embodiment inspiradas en la fenomenología ofrecían un "compañero dialéctico" para las aproximaciones estructuralistas y posestructuralistas sobre la textualidad, y si bien él no profundizó en las implicancias metodológicas de esa dialéctica, alentó el examen futuro de estas relaciones. Por eso, consideré necesario confrontar la descripción fenomenológica cultural de las corporalidades actuales

\section{Estas aproximaciones} a la corporalidad también se fundamentaron en otras dos fuentes metodológicas: la misma experiencia de trabajo de campo, concebida como una experiencia intersubjetiva dialéctica, y la tradición hermenéutica en W. Dilthey y especialmente en P. Ricoeur. con la explicación de sus genealogías, incluyendo sus relaciones con otras prácticas sociales y técnicas corporales.

Estas aproximaciones a la corporalidad también se fundamentaron en otras dos fuentes metodológicas: la misma experiencia de trabajo de campo, concebida como una experiencia intersubjetiva dialéctica, y la tradición hermenéutica en W. Dilthey y especialmente en P. Ricoeur. En primer lugar, examiné cómo estos dos movimientos analíticos también caracterizan la principal premisa metodológica del trabajo de campo: la observación participante. En efecto, la observación participante involucra dos movimientos intersubjetivos conectados, pero a la vez parcialmente antagónicos: por un lado, acercarse y participar en la dinámica de los contextos sociales estudiados, lo cual generalmente requiere que se desempeñen, aunque sea transitoriamente, otros roles, actitudes y prácticas diferentes de las de un 
mero observador externo al fenómeno; por otro, seguir observando, entendiendo esta actividad como un distanciamiento reflexivo, un esfuerzo por objetivar aquella dinámica social en la que temporalmente se está incluido. Si bien participación y observación en alguna medida se superponen, el movimiento de acercamiento que subyace a la primera y el distanciamiento que posibilita la segunda, por su carácter antagónico, suelen presentar dimensiones conflictivas. Diversos autores coinciden en que la productiva riqueza de la metodología etnográfica reside en esta tensión y complementariedad entre ambos movimientos. Como ya destacó Geertz (1987), aludiendo al círculo hermenéutico, el etnógrafo debería moverse en una espiral entre generalizaciones y observaciones específicas, entre las observaciones desde afuera y el entendimiento del punto de vista nativo desde adentro. Justamente, otra de las fuentes para repensar esta tensión metodológica provino de las discusiones de la tradición filosófica hermenéutica, que también fue concebida como un campo dialéctico, especialmente en los trabajos de Ricoeur (1999). Así, este autor proponía una "confrontación" entre la "comprensión" que provee la denominada por él "hermenéutica de la revelación”, cercana a la fenomenología, y las "explicaciones" que postulan las "hermenéuticas de la sospecha", que, como vimos, el autor reconoce en Nietzsche, Freud y Marx, y que extendimos a sus continuadores posestructuralistas, como Foucault, Lacan, Laclau y Butler".

Pasemos a especificar entonces ambos movimientos analíticos. El primer movimiento de acercamiento consiste en describir los patrones de uso del cuerpo más recurrentes dentro del grupo y/o práctica social estudiada. Para ello, es importante poner en relación los aspectos perceptibles del cuerpo o la imagen corporal, así como las formas que adquiere la postura, la gestualidad y el movimiento, temáticas que han sido exploradas inicialmente por Laban (1958). Un segundo movimiento de acercamiento consiste en describir cómo estos cuerpos se articulan temporal y espacialmente unos con otros y también con los objetos, según los diferentes roles, es decir, cómo se organizan en cuanto prácticas realizadas en un entorno. Los estudios del ritual y luego de la performance llamaron especialmente la atención sobre la importancia de atender a estas dimensiones de las prácticas corporales. Asimismo, el detallado análisis de Foucault (1987) de los "cuerpos dóciles" permitió destacar cómo, en las principales instituciones de la modernidad occidental, las prácticas corporales cotidianas se organizaban temporo-espacialmente e involucraban una peculiar "composición de las fuerzas" de cada grupo. Finalmente, agregaría que especialmente los estudios ligados al interaccionismo simbó-

\footnotetext{
Es importante agregar que esta metodología dialéctica no implica una simplificación o eliminación de las contradicciones entre estos abordajes. Por el contrario, reconoce sus especificidades y diferencias para, por medio de un contraste radical, arribar a una nueva síntesis. Aunque estas perspectivas suponen diferentes ontologías -el ser-en-el-mundo constituyente y el sujeto históricamente constituido-, esto no nos lleva a descartar los aportes de sus métodos -parciales e insuficientes, cuando se aplican por sí solos-, sino a asumir el desafío de articularlos dialécticamente, para lograr una mayor comprensión. Como sostienen Ollman y 5mith (2008: 3), retomando a Hegel, este es uno de los principales desafíos de un pensamiento dialéctico: "reconocer que las posiciones aparentemente opuestas solo ofrecen reportes unilaterales de una realidad compleja. La verdad es el todo"; por tanto, deberíamos poder "encontrar un lugar en nuestro pensamiento para todas esas verdades parciales y unilaterales".
} 
lico, como los trabajos de Hall (1968) sobre la "proxémica" y los de Goofman (1970) sobre los "rituales de interacción", ofrecen interesantes pistas para analizar estas dimensiones de la corporalidad.

Ahora bien, si nos restringiéramos solamente al análisis de estas variables, centradas en las formas externas, nuestra estrategia de acercamiento quedaría circunscripta a una mirada externa del cuerpo como mero objeto. Por tanto se propone un nuevo acercamiento, para aproximarnos al modo en que se experimentan o vivencian intersubjetivamente esas corporalidades. De este modo, retomando las tradiciones fenomenológicas antes mencionadas, he intentado resaltar que la descripción de las formas que adquiere la imagen y el movimiento corporal debe complementarse con la descripción de la experiencia sensible, emotiva y significante que promueve, pues toda experiencia humana implica un continuum entre movimiento, sensorialidad, sentimientos y significación, el cual, si bien es posible separar analíticamente en un movimiento de objetivación, no suele escindirse tan fácilmente en el flujo de la experiencia cotidiana [Citro, 1997; 2003; 2009]5. Cabe destacar que, en el ámbito latinoamericano, especialmente las etnografías de colegas brasileños, como José Bizerril (2007) y Miriam Rabelo (2005), o argentinos, como Aschieri y Puglisi (2010), Rodríguez (2010), Sirimarco (2010) y Soich (2010), han enfatizado en este tipo de abordajes fenomenológicos centrados en la experiencia

Ahora bien, en un estudio socioantropológico hay otro cuerpo que debería ser también descripto: el del propio investigador. Por eso creemos que en estos movimientos de acercamiento es fundamental poder incluir también el análisis de la propia corporalidad, por ejemplo durante la experiencia en el trabajo de campo. A partir de este ejercicio de autodescripción, es posible comenzar a reflexionar sobre los propios habitus del etnógrafo, así como sobre los supuestos que subyacen a su práctica, cuestión que Aschieri (2013) ha trabajado especialmente. [abe recordar también que cada vez más diferentes autores destacan la importancia de un involucramiento más activo de los etnógrafos en el trabajo de campo, que incluya el movimiento corporal y los diferentes sentidos. Esto ya tempranamente lo sostuvo Jackson: "la participación corporal en las tareas prácticas cotidianas fue una técnica creativa, la cual siempre me ayudó a fundamentar el sentido de una actividad, usando mi cuerpo como otros lo hacían" (1983: 340). Tiempo después, Wacquant (2006) también planteó la necesidad de una "participación observante" en un sentido similar, cuando se entrenó con los boxeadores norteamericanos que pretendía estudiar, y diversas etnografías latinoamericanas retomarán estas metodologías participativas.

Tal vez por esa inescindibilidad es que la palabra "sentido" adquiere una triple significación en la lengua castellana: como órgano-modo de percepción sensorial (el "sentido" de la vista, el tacto, etc.), como aquello que se experiencia en términos de sentimiento (por ejemplo, el amor "sentido" por una persona) y como significación de un discurso (el "sentido" dado a una frase).

En Colombia, el trabajo de Luz Elena Gallo Cadavid (2010), también destacó la importancia de la perspectiva fenomenológica, aunque en su caso se centra en los discursos conceptuales sobre la Educación Física. Por otra parte, en México, Ferreiro Perz (2002) resaltó los aportes fenomenológicos para comprender al cuerpo que danza. 
Una vez realizada esta descripción de las corporalidades, es posible empezar a elaborar hipótesis acerca de cómo algunos de sus rasgos, desde la imagen corporal a determinados gestos, maneras de moverse o sentir, suelen constituirse en marcas indicadoras o, a veces, invisibilizadoras de diferentes roles sociales, estatus y/o jerarquías dentro del grupo o práctica, o también en diacríticos identitarios de posiciones de género, étnicas, raciales, etarias, 0 de condiciones sociales como clase, adscripción religiosa, profesional, etc. Asimismo, podemos también partir de que estas prácticas suelen ser utilizadas por los actores para reforzar o legitimar esos roles y posiciones identitarias o también para intentar transformarlas. Pero, para empezar a confrontar estas hipótesis, consideramos que es necesario examinar cómo se fueron generando esos entramados que asocian determinados movimientos con sensaciones, emociones y sentidos específicos. Para ello, debemos dejar por un momento la descripción y comprensión de estos cuerpos actuales y pasar a nuestro segundo movimiento analítico, el del distanciamiento.

Aquí, nos proponemos explicar cómo un grupo social ha llegado a construir su imagen corporal, mover sus cuerpos, sentirlos y significarlos de una manera específica, trazando una genealogía que incluye no solo la historia de la práctica específica analizada, sino también sus conexiones pasadas y presentes con otras prácticas sociales y modalidades corporales. Es decir, se examinan los discursos y prácticas corporales de aquellos otros grupos y espacios sociales con los que las personas se han vinculado a lo largo de su historia, para intentar explicar cómo estos han influido en la construcción de esos cuerpos y discursos actuales. En América Latina, especialmente los trabajos de Zandra Pedraza Gómez (1996) fueron pioneros en destacar la importancia de estos abordajes genealógicos en el estudio de las corporalidades. De nuestra parte, agregaríamos que, al igual que en el movimiento analítico anterior, este análisis genealógico también podría aplicarse al propio investigador, cuestión a la que intenté aproximarme en la primera parte, al definir algunas de las genealogías personales que incidieron en mis posicionamientos teórico-metodológicos?.

A partir del análisis genealógico, puede verse cómo ciertos elementos de una performance, habitus o discurso se descontextualizan y recontextualizan en otro, tal como han destacado los abordajes de la intertextualidad, que en nuestro caso extendemos a un abordaje de la intercoporeidad ${ }^{8}$. Así, al examinar los modos en que los sujetos se apropian de estos elementos discursivos y corporales, reconfigurando y/o resignificando algunos, enmascarando y/o negando otros, pueden obtenerse indicios sutiles -pues no siempre se verbalizan espontáneamente ni son objeto de reflexión consciente- que develan sus posicionamientos sociales más amplios, así como sus intentos por legitimarlos o modificarlos.

Este análisis fue inspirado en la tesis de Aschieri (2013), quien destacó la importancia de reflexionar sobre los modos en que las trayectorias corporales e intelectuales del etnógrafo inciden en sus análisis.

8 Retomando una propuesta de [sordas (1994:12), proponemos combinar la noción semiótica de intertextualidad, apelando a los trabajos de Bajtin (1985), Voloshinov (1993), Briggs and Bauman (1996), y la noción Fenomenológica de intersubjetividad, entendida primariamente como una intercorporeidad. 
Este análisis nos conduce al movimiento final de síntesis, en el que se propone analizar cómo esas prácticas y significaciones, ya genealógicamente situadas, se ponen en juego en la vida social actual. Especialmente los abordajes inspirados en la semiótica peirceana permiten analizar cómo aquellas imágenes, movimientos y sonoridades que remiten a otras prácticas o a ejecuciones pasadas, al ser recontextualizados, suelen operar como signos icónicos o indéxicos que, a través de relaciones de analogías o coocurrencia, crean diversas "significaciones". Lo interesante es que en esta perspectiva semiótica, que a su vez se vincula a la fenomenología y al pragmatismo, las significaciones se entienden como "efectos" que pueden adquirir la forma de ideas o conceptos lingüísticamente basados, pero también de "sentimientos y reacciones físicas" (Turino, 1999). En suma, los estilos de movimientos de un habitus, la imagen corporal o las danzas, suelen extraer su fuerza performativa y significante de estas conexiones genealógicas y contextuales que se reiteran a lo largo del tiempo. Y en estas continuas citas y reiteraciones, tanto los discursos como las corporalidades pueden ser reproducidos y legitimados, pero también reconfigurados o incluso subvertidos; de ahí su capacidad para incidir en nuestras posiciones identitarias y relaciones sociales?.

\section{Saberes en perspectiva dialéctica: Hacia una síntesis ENTRE LOS DISCURSOS Y EL MOVIMIENTO}

Desde la perspectiva que aquí hemos esbozado, se reconoce la corporalidad como una dimensión activa y constituyente de nuestra comprensión del mundo, así como de las prácticas de subjetivación y de la construcción de nuestras posiciones identitarias. De ahí deriva entonces la importancia de reconstruir las propias experiencias corporales, geopolíticamente situadas, examinando el lugar que estas han ocupado en nuestras producciones académicas o artísticas. En la medida en que podamos efectuar estas autoetnografías genealógicas, incluyendo la corporalidad, podremos comprender, como decíamos al inicio, parafraseando a Nietzsche, cómo han sido "paridos" nuestros pensamientos, desde nuestros seres encarnados en los múltiples devenires de un mundo.

Asimismo, en este movimiento de sospecha advertimos más claramente el carácter socialmente construido de nuestros habitus académicos, y ello nos permite su cuestionamiento y transformación, en modos que resulten más coherentes con nuestros deseos y también con nuestras posturas epistemológicas y políticas. En otras palabras, si reconocemos que el cuerpo interviene activamente en la producción de pensamientos, saberes y subjetividades, cabe preguntarse por los modos concretos como hemos utilizado nuestros cuerpos a lo largo de la vida, incluyendo también nuestras prácticas académicas, y cómo estos modos han incidido en la producción de nuestras teorías. No es casual entonces que las prácticas de ese cuerpo más parcializado, pasivo e individual de la lectoescritura y de la oralidad expo-

Aquí tendemos un puente entre los análisis de la performatividad centrados en el discurso, inspirados en Butler (1999, 2002), y una performatividad corporal y musical, inspirada en la semiótica de Peirce y otros autores que los retoman, como Feld (1994) y Turino (1999). 
sitiva tradicional hayan sido correlativas con el predominio de un pensamiento sobre el cuerpo, entendido inicialmente como mero instrumento de la mente y luego como pura materialidad objeto de relaciones de poder. En contraste, si con el pensamiento académico de las últimas décadas hemos llegado a entender el cuerpo como encarnación de nuestra agencia e intersubjetividad, es también porque lo hemos vivenciado de otros modos, por la época y el lugar en el que nos tocó vivir, pero también por las prácticas que hemos elegido ${ }^{10}$. No obstante, dada la poderosa fuerza de los habitus institucionales, en nuestro caso pasaron casi diez años hasta que ese otro cuerpo vivido, el del arte y el ritual, pudo empezar a transitar también por el espacio académico. Así intentamos nuevas síntesis que revaloricen las experiencias sensorio-perceptivas y los movimientos corporales de carácter intersubjetivo o grupal provenientes de diversas culturas, a la manera de una compañera dialéctica de las formas de lectoescritura y oralidad individual, heredadas de la colonialidad-modernidad occidental.

Por qué insistimos en intentar estas síntesis. Por un lado, porque desde nuestra posición como académicos latinoamericanos subrayamos la importancia epistemológica y también política de poder recuperar estos otros saberes locales, que a menudo han sido desvalorizados por las tradiciones académicas occidentales. En este sentido, las teorías sobre la colonialidad/modernidad y la decolonialidad en América Latina contribuyeron a destacar el rol fundamental de la expansión colonial en la legitimación de la racionalidad tecnocientífica moderna, que desde el siglo XVIII se convirtió en el único modelo válido de producción de conocimiento, dejando por fuera cualquier otro tipo de epistemes generadas en los territorios coloniales (Lander, 2005; Mignolo, 2005; Dussel, 2000; Quintero y Petz, 2009). Justamente, sostenemos que, en este movimiento de prescindencia de estos otros saberes vinculados a los mundos indígenas y afroamericanos, se excluyó la posibilidad de considerar la corporalidad como una vía legítima de producción de conocimiento, reduciendo su participación sobre todo a los sentidos de la vista y el oído, desde una "perspectiva" que resaltaba la importancia de la observación, la escucha y la distancia, como fuentes de una supuesta "objetividad". No obstante, estos saberes indígenas y afroamericanos excluidos involucran prácticas en las que los demás sentidos (gusto, olfato, tacto, cenestesia), junto con la gestualidad y el movimiento corporal, también ocupan un lugar fundamental. Por tanto, la incorporación de estas otras vías de conocimiento permite no solo ampliar el potencial heurístico de nuestras investigaciones, así como sus modos de enseñarlas y difundirlas, sino que también contribuye a cuestionar y renovar nuestros habitus académicos, aún tan profundamente colonizados.

Por otro lado, en términos prácticos, estas experiencias de integración aportan a una mayor y más encarnada comprensión de los temas que se discuten en los congresos o espacios docentes. Asimismo, suelen generar un clima de reflexión y discusión colectiva mucho más favorable que los modos expositivos tradicionales, pues las experiencias

10 En otro trabajo (Citro, 2010), intentamos vincular los cambios en las teorías socio-antropológicas sobre el cuerpo con las transformaciones de las experiencias concretas de los cuerpos en el mundo.

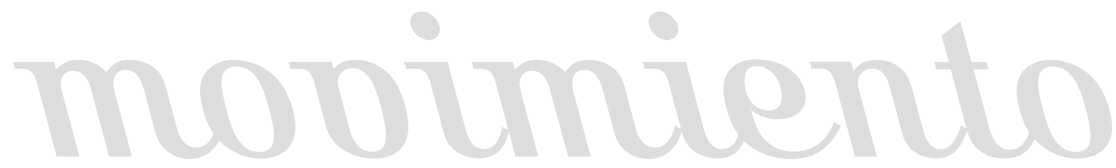


corporales que se ponen en juego facilitan los vínculos intersubjetivos y el compromiso de los estudiantes o audiencias en estos espacios, en cuanto pasan a tener un rol más activo y participativo que el de meros receptores de una clase o ponencia. También, ciertas actividades colectivas facilitan relaciones sociales más horizontales y colaborativas de construcción de los saberes frente a los modos jerárquicos y competitivos que aún dominan nuestros espacios institucionales. Finalmente, notamos que se genera una mayor alegría y disfrute al desarrollar estas actividades, que se ven investidas así de dimensiones lúdicas y creativas, tantas veces ausentes en el mundo académico.

\section{Hacia UNA REFLEXIÓN-PERFormance final}

Después de haber sido parte del movimiento de danza-teatro independiente de Buenos Aires y del giro corporal en el campo académico latinoamericano de fines de los años noventa, y de haber tenido algunos tropiezos y caídas durante estas distintas travesías, actualmente estamos transitando este salto utópico, que esperamos que nos permita ya no solo re-mover los pensamientos sobre el cuerpo en las ciencias sociales y las humanidades, sino también re-mover creativamente nuestros movimientos corporales en ellas. Como vimos, se trata de darnos la posibilidad de comenzar a reflexionar desde nuevas modalidades corporales que integren los diversos lenguajes estéticos de las performances (sonoros y musicales, gestuales, teatrales y dancísticos, visuales, poéticos...), para co-construir así una ciencia que, además de reflexiva, también pueda empezar a ser más perceptiva y más alegremente transformadora y embellecedora de las vidas.

Por eso, y ya para concluir, queremos contarles que la conferencia del Encuentro del Giro Corporal que dio origen a este artículo y también otras que hemos compartido luego incluyeron en su desarrollo performances colectivas con los asistentes.

Objetivo: Invitar a los asistentes a ensayar, en la misma práctica, algunos elementos de la metodología dialéctica de "acercamiento-distanciamiento" a las corporalidades que aquí se ha descripto, a partir de un ejercicio performativo intersubjetivo entre dos. Además, el ejercicio tiene la intención de explorar la complementariedad de los modos de registro y comunicabilidad a través de la percepción sensorial, la gestualidad y el movimiento, por un lado, y la escritura, por el otro. 


\section{Programa de actividades:}

1. Se invita a los asistentes a trabajar con el compañero/a que tengan a su lado, a que se saluden y presenten unos a otros.

2. Se les pide que cierren los ojos: escuchen los sonidos del cuerpo del compañero, su respiración, recuerden su voz. Luego, que huelan los olores de la sala y los de sus compañeros, sientan el gusto en sus bocas, tomen la mano del compañero y sientan su temperatura, su tono muscular, su textura.

3. Nos soltamos, abrimos los ojos y recorremos con la mirada la imagen corporal del compañero, sus formas, sus colores, sus tratamientos aplicados al cuerpo.

4. Volvemos a cerrar los ojos y recapitulamos toda esta información sensorial.

5. Les pedimos que abran los ojos y que, en unas tarjetas que les repartimos, en el lado que dice "acercamiento-participación", escriban unas breves palabras para describir la corporalidad del compañero, la voz que escucharon, los olores que olieron, la piel que tocaron, la imagen corporal que vieron, aunque seguramente no podrán describir el gusto, porque eso hubiera implicado transgredir los códigos de contacto que rigen en nuestras sociedades.

6. Les solicitamos que guarden la tarjeta momentáneamente y que vuelvan a cerrar los ojos. Se pide que cada uno elija una experiencia de su propio pasado, de su experiencia encarnada, que considere que haya sido significativa para lo que hoy es como persona..., para su corporalidad. Seguramente habrá muchas de estas experiencias, pero se elegirá una; puede ser la primera que haya venido a la memoria, la que se considere más determinante, la que los haya marcado profesionalmente... Y, una vez más, tratar de recordar qué sensaciones, posturas, gestos, movimientos corporales y emociones están vinculados a esa experiencia, tratando de reconstruir en su cuerpo cómo se encarnó en ustedes esa experiencia.

7. Finalmente, les pedimos que abran los ojos y que traten de contar la experiencia elegida a su compañero, pero que lo hagan con el cuerpo, solo con mímica y sonidos, no con lenguajes articulados. Es decir, durante el intercambio, no le decimos al compañero cuál es esa experiencia, sino que se la contamos con el cuerpo, y cada uno va a anotar en la parte de atrás de la tarjeta, donde dice "distanciamiento-observación", algunas palabras sobre lo que observa en los gestos y movimientos del compañero. 
8. Le regalan su tarjeta al compañero, la leemos y conversamos libremente sobre la experiencia, prestando especial atención a las similitudes y diferencias entre: la percepción sensorial de nuestro cuerpo actual y la recreación de una experiencia significativa del pasado; la información que obtuvimos de la expresividad corporal y la que obtuvimos del diálogo hablado.

\section{Referencias}

Alcoff, L. M. (2000). Merelau-Ponty and feminist theory of experience. En F. Evans y Leonard Lawlow (eds.), Chiasms: Merleau-Ponty's notion of Flesh. Nueva York: Sunny, pp. 251-272.

Aschieri, P. (2013). Subjetividades en movimiento: reapropiaciones de la danza butoh en Argentina. Tesis de Doctorado en Antropología, Facultad de Filosofía y Letras, Universidad de Buenos Aires. Buenos Aires: UBA.

Aschieri, P. y R. Puglisi (2010). Cuerpo y producción de conocimiento en el trabajo de campo: Una aproximación desde la fenomenología, las ciencias cognitivas y las prácticas corporales orientales. En 5. Citro (comp.), Cuerpos plurales. Ensayos antropológicos de y desde los cuerpos. Buenos Aires: Biblos.

Bajtin, M. (1985). Estética de la creación verbal [1952]. México: Siglo XXI. (1994). La cultura popular en la Edad Media y en el Renacimiento. El contexto de Francois Rabelais [1930]. Buenos Aires: Alianza.

Bizerril, J. (2007). 0 retorno à raiz: uma linhagem taoísta no Brasil. San Paulo: Attar.

Briggs, Ch, y R. Bauman (1996). Género, intertextualidad y poder social. Revista de Investigaciones Folklóricas, 11 , pp. 78-108.

Butler, J. (1999). El género en disputa. El feminismo y la subversión de la identidad. México: Paidós-PUEG.

____ (2002). Cuerpos que importan: Sobre los límites materiales y discursivos del "sexo". Buenos Aires: Paidós.

Citro, 5. (1997). Cuerpos festivo-rituales: un abordaje desde el rock. Tesis de Licenciatura, Departamento de Ciencias Antropológicas, Facultad de Filosofía y Letras. Buenos Aires: UBA.

(1999). La multiplicidad de la práctica etnográica: Reflexiones en torno a una experiencia de campo en comunidades tobas. Cuadernos del Instituto Nacional de Antropología y Pensamiento Latinoamericano, 18, pp. 91-107. 
___ (2003). Cuerpos significantes: Una etnografía dialéctica con los toba takshik. Tesis de Doctorado en Antropología, Universidad de Buenos Aires. Buenos Aires: UBA.

___ (2009). Cuerpos significantes. Travesías de una etnografía dialéctica. Buenos Aires: Biblos.

(2012). Ritual Transgression and Grotesque Realism in 1990s Rock Music. An ethnographer among the Bersuit. En Pablo Vila y P. Semán (eds.), Youth Identities and Argentine Popular Music: Beyond Tango. Nueva York: Palgrave Macmillan, pp. 19-40.

(en prensa). Hacia una perspectiva interdisciplinaria sobre la eficacia ritual: corporalidad, emoción y goce. En P. 0. Ari y Marcelo Tadvald (eds.). XVII Jornadas sobre alternativas religiosas en América Latina. Porto Alegre: Brasil.

[itro, 5. y P. Aschieri (eds.) (2012). Cuerpos en movimiento. Antropología de y desde las danzas. Buenos Aires: Biblos.

Citro, Silvia, P. Aschieri y Y. Mennelli (2011). El multiculturalismo en los cuerpos y las paradojas de la desigualdad poscolonial. Boletín de Antropología, 25 (42), pp. 103-128. Colombia: Universidad de Antioquía.

Citro, S., M. Lucio y R. Puglisi (en prensa). Hacia una perspectiva interdisciplinar sobre la corporeidad: Los habitus, entre la filosofía, la antropología y las neurociencias. En Elsa Muñiz (comp.), Heurísticas del cuerpo. Consideraciones desde América Latina. México: La Cifra- El cuerpo descifrado.

Crossley, N. (1996). Body-Subject/Body-Power: agency, inscription and control in Foucault and Merleau-Ponty. Body E Society, 2, 99.

[sordas, T. (1993). Somatic Modes of Attention. Cultural Anthropology, 8 (2), pp. 135-156.

(1994). Introduction: The Body as Representation and Being-in-the-World. En T. Csordas (ed.), Embodiment and Experience. [ambridge University, pp. 1-24.

Dussel, E. (2000). Europa, modernidad y eurocentrismo. En E. Lander (comp.), La colonialidad del saber: eurocentrismo y ciencias sociales. Perspectivas Latinoamericanas. Buenos Aires: Clacso.

Feld, 5. (1994). Aesthetics as iconicity of style (uptown title); or (downtown title) "Lift up-over sounding": geeting into the Kaluli Groove. En Ch. Keil y Steven Feld (eds.), Music Grooves. Chicago: The University of Chicago, pp. 109-150.

Ferreiro Pérez, A. (2002). Una perspectiva fenomenológica del cuerpo que danza. En M. Ramos Smith y P. Cardona Lang [eds.], La danza en México. México: Instituto Nacional de Bellas Artes/Lenidi, pp. 127-143.

Foucault, Michel (1987). Vigilar y castigar [1975]. Buenos Aires: Siglo XXI. 